\title{
Identification of Novel Cross-Talk between the Neuroendocrine and Autonomic Stress Axes Controlling Blood Pressure
}

\author{
Khalid Elsaafien, ${ }^{1,3 *}{ }^{\circ}$ Matthew K. Kirchner, ${ }^{5,6 *}$ Mazher Mohammed, ${ }^{1}$ Sophia A. Eikenberry, ${ }^{2}$ Chloe West, ${ }^{5,6}$ \\ Karen A. Scott, ${ }^{1,3}{ }^{(0)}$ Annette D. de Kloet, ${ }^{2,3,4}$ Javier E. Stern, ${ }^{5,6}$ and Eric G. Krause ${ }^{1,3,4}$ \\ ${ }^{1}$ Department of Pharmacodynamics, College of Pharmacy, University of Florida, Gainesville, Florida 32611, ${ }^{2}$ Department of Physiology and Functional \\ Genomics, College of Medicine, University of Florida, Gainesville, Florida 32611, ${ }^{3} \mathrm{Center}$ of Integrative Cardiovascular and Metabolic Diseases, University of \\ Florida, Gainesville, Florida 32611, ${ }^{4} \mathrm{McKnight}$ Brain Institute, University of Florida, Gainesville, Florida 32611, ${ }^{5}$ Neuroscience Institute, Georgia State \\ University, Atlanta, Georgia 30302, and ${ }^{6}$ Center for Neuroinflammation and Cardiometabolic Diseases, Georgia State University, Atlanta, Georgia 30302
}

The hypothalamic paraventricular nucleus (PVN) controls neuroendocrine axes and the autonomic nervous system to mount responses that cope with the energetic burdens of psychological or physiological stress. Neurons in the PVN that express the angiotensin Type la receptor $\left(\mathrm{PVN}^{\mathrm{Agtrla}}\right)$ are implicated in neuroendocrine and autonomic stress responses; however, the mechanism by which these neurons coordinate activation of neuroendocrine axes with sympathetic outflow remains unknown. Here, we use a multidisciplinary approach to investigate intra-PVN signaling mechanisms that couple the activity of neurons synthesizing corticotropin-releasinghormone (CRH) to blood pressure. We used the Cre-Lox system in male mice with in vivo optogenetics and cardiovascular recordings to demonstrate that excitation of PVN ${ }^{\mathrm{Agtrla}}$ promotes elevated blood pressure that is dependent on the sympathetic nervous system. Next, neuroanatomical experiments found that $\mathrm{PVN}^{\text {Agtrla }}$ synthesize $\mathrm{CRH}$, and intriguingly, fibers originating from PVN ${ }^{\text {Agtrla }}$ make appositions onto neighboring neurons that send projections to the rostral ventrolateral medulla and express CRH type 1 receptor (CRHR1) mRNA. We then used an ex vivo preparation that combined optogenetics, patch-clamp electrophysiology, and $\mathrm{Ca}^{2+}$ imaging to discover that excitation of PVN ${ }^{\mathrm{Agtrla}}$ drives the local, intra-PVN release of $\mathrm{CRH}$, which activates rostral ventrolateral medulla-projecting neurons via stimulation of CRHR1(s). Finally, we returned to our in vivo preparation and found that CRH receptor antagonism specifically within the PVN lowered blood pressure basally and during optogenetic activation of PVN ${ }^{\text {Agtrla }}$. Collectively, these results demonstrate that angiotensin II acts on PVN ${ }^{\text {Agtrla }}$ to conjoin hypothalamic-pituitary-adrenal axis activity with sympathetically mediated vasoconstriction in male mice.

Key words: autonomic; cardiovascular; glucocorticoids; HPA axis; hypertension; stress

Significance Statement

The survival of an organism is dependent on meeting the energetic demands imposed by stressors. This critical function is accomplished by the CNS's ability to orchestrate simultaneous activities of neurosecretory and autonomic axes. Here, we unveil a novel signaling mechanism within the paraventricular nucleus of the hypothalamus that links excitation of neurons producing corticotropin-releasing-hormone with excitation of neurons controlling sympathetic nervous system activity and blood pressure. The implication is that chronic stress exposure may promote cardiometabolic disease by dysregulating the interneuronal cross-talk revealed by our experiments.

Received Jan. 31, 2021; revised Apr. 1, 2021; accepted Apr. 5, 2021

Author contributions: K.E., M.K.K., K.A.S., A.D.d.K., J.E.S., and E.G.K. designed research; K.E., M.K.K., M.M., S.A.E., C.W., K.A.S., A.D.d.K., J.E.S., and E.G.K. performed research; K.E., A.D.d.K., J.E.S., and E.G.K. contributed unpublished reagents/analytic tools; K.E., M.K.K., M.M., C.W., K.A.S., A.D.d.K., J.E.S., and E.G.K. analyzed data; K.E., J.E.S., and E.G.K. wrote the first draft of the paper; K.E., M.K.K., M.M., K.A.S., A.D.d.K., J.E.S., and E.G.K. edited the paper; K.E. and E.G.K. wrote the paper.

This work was supported by American Heart Association (AHA) Grant 17GRNT33660969; and National Institutes of Health Grants HL125805 and HL145028 to A.D.d.K., HL136595, HL096830, and HL122494 to E.G. K., and HL090948 and NS094640 to J.E.S.

${ }^{*}$ K.E. and M.K.K. contributed equally to this work.

The authors declare no competing financial interests.

Correspondence should be addressed to Eric G. Krause at ekrause@cop.ufl.edu or Javier E. Stern at jstern@gsu.edu.

https://doi.org/10.1523/JNEUROSCI.0251-21.2021

Copyright $\odot 2021$ the authors

\section{Introduction}

Survival of an organism is dependent on meeting the energetic demands imposed by stressors, defined broadly, as real or perceived threats to homeostasis. The CNS coordinates the activity of neuroendocrine axes and the autonomic nervous system to initiate cardiometabolic responses that anticipate the energetic burdens associated with psychological or physiological threats. While the secretagogues, nuclei, and ganglia controlling the neuroendocrine and autonomic nodes of the stress response are well established (Ulrich-Lai and Herman, 2009), the signaling mechanism(s) governing their integration and coordination remains to be elucidated. 
The paraventricular nucleus of the hypothalamus (PVN) is recognized as a key integrative center that moderates cardiometabolic function to cope with homeostatic threats (Sladek et al., 2015). As such, the PVN contains anatomically and functionally distinct neuronal phenotypes that release neuroendocrine factors into the systemic circulation or regulate sympathetic outflow to cardiovascular tissues (Swanson and Sawchenko, 1980). The firing activity of these neuronal phenotypes controls the neurosecretory and sympathetic outflows from the PVN (Cazalis et al., 1985; Chen and Toney, 2010; Holbein et al., 2018) and is finetuned by the combined action of intrinsic properties (e.g., ionic conductance) or extrinsic properties (e.g., synaptic connectivity) (Bourque et al., 1993; Brown et al., 2013; Colmers and Bains, 2018). While the intrinsic and extrinsic mechanisms governing the firing and output of each independent neuronal phenotype are generally well understood, the local signals that coordinate their activities to enable multimodal neuroendocrine and autonomic responses to homeostatic threats remain largely unknown. In this regard, we discovered that within the PVN, the firing of vasopressin neurons is accompanied by dendritic release of vasopressin that creates a paracrine signal which couples the secretion of vasopressin into the systemic circulating with augmented sympathetic outflow to the cardiovascular system (Son et al., 2013). Still, whether the coordinated activities of the hypothalamic-pituitary-adrenal (HPA) axis and sympathetic outflow typically observed in the context of the stress response also involves a local interpopulation signaling mechanism has not been discerned.

Within the PVN, the neuropeptide, angiotensin-II, and its angiotensin Type 1a receptors (Agtrla) have long been implicated in orchestrating neuroendocrine and autonomic responses to stress (Jezova et al., 1998; Saavedra et al., 2004). Recent studies from our laboratories using genetically modified mice have found that the activity of neurons in the PVN that synthesize Agtrla(s) is intimately coupled to the neuroendocrine and cardiovascular nodes of the stress response (de Kloet et al., 2017). Specifically, selective optogenetic excitation of Agrtla-expressing neurons in the PVN ( $\mathrm{PVN}^{\text {Agtrla }}$ ) promotes activation of the HPA and hypothalamic-pituitary-thyroid (HPT) axes, whereas optogenetic inhibition of these neurons elicits the opposite effect (de Kloet et al., 2017). Interestingly, optogenetic excitation was also found to increase systolic blood pressure (SBP) (de Kloet et al., 2017); however, selective deletion of Agtrla(s) from the PVN blunts cardiovascular reactivity and indices of sympathetic nervous system activity (SNA) during psychogenic stress (L. Wang et al., 2016). Collectively, these results suggest that, during stress, PVN $^{\text {Agtrla }}$ couple activation of neuroendocrine axes mediating energy utilization with the increased sympathetic outflow and cardiovascular reactivity that is a hallmark of the fight-or-flight response. However, the precise signaling mechanisms that couple the activity of PVN ${ }^{\text {Agtrla }}$ to alterations in autonomic outflow that affect cardiovascular function remain to be identified.

To address this gap, we implement a multidisciplinary approach based on the complementary use of (1) in vivo optogenetics and telemetric cardiovascular recordings, (2) genetic reporting, fluorescence ISH, and neuronal tract-tracing, and (3) ex vivo optogenetics, patch-clamp electrophysiology, and $\mathrm{Ca}^{2+}$ imaging. We reveal a novel signaling mechanism that couples the activity of neurons regulating the HPA axis and sympathetically mediated vasoconstriction. We propose that this novel interneuronal cross-talk has important implications for mounting responses that cope with acute threats to homeostasis, but also contribute to the neuroendocrine and autonomic dysregulation that occurs with cardiometabolic diseases that follow chronic stress exposure.

\section{Materials and Methods}

Animals. Studies were conducted in male mice on a C57BL/6J background or in Wistar male rats ( $n=4$, purchased from Harlan, 4-5 weeks old). Mice were 8-10 weeks old at the initiation of the studies. All animals were maintained in temperature and humidity-controlled rooms on 12:12 h light-dark cycles. In all cases, food and water were available ad libitum. All procedures were approved by the Institutional Animal Care and Use Committees at the University of Florida or Georgia State University and were conducted in accordance with the National Institutes of Health's Guide for the care and use of laboratory animals.

The majority of studies were conducted using an Agtrla-Cre knockin mouse line. These mice were generated by Biocytogen and the University of Florida, were extensively validated (de Kloet et al., 2017), and have been made available at The Jackson Laboratory (stock $\# 030553$ ). In one study, mice homozygous for this Agtr1a-Cre knock-in gene were bred with mice heterozygous for the Ai32 stop-flox-ChR2eYFP gene (The Jackson Laboratory, stock \#024109). This leads to two genotypes of offspring: (1) mice that express the light-sensitive channel2 rhodopsin (ChR2) and enhanced yellow fluorescent protein (eYFP) in all cells that express the Agtrla (referred to as Agtr1a-ChR2 mice) and (2) their littermates that express only the Agtrla-Cre gene that serve as controls for the cardiovascular studies depicted in Figure 1.

Initial neuroanatomical studies used mice that have the red fluorescent protein variant, tdTomato, directed to either corticotrophin-releasing hormone $(\mathrm{CRH})$-containing cells or Agtrla-containing cells. These lines are referred to as CRH-tdTomato or Agtrla-tdTomato mice, respectively. To generate $\mathrm{CRH}$-tdTomato mice, $\mathrm{CRH}$-Cre knock-in mice (The Jackson Laboratory, stock \#012704) were crossed with stop-floxtdTomato mice (The Jackson Laboratory, stock \#007914). The fidelity of this approach to label CRH neurons residing in the PVN was previously validated (Smith et al., 2014). The same approach was used to generate Agtr1a-tdTomato mice, which we have previously found exhibit $97 \%$ overlap between tdTomato and Agtrla-mRNA within the PVN (de Kloet et al., 2017).

Viral constructs. Adeno-associated viral vectors (AAVs) that allow for the Cre-inducible expression of fluorophores (eYFP or mCherry) and/or light sensitive ion channels were obtained from the viral vector core at the University of North Carolina. For expression of eYFP and ChR2, pAAV2-EF1a-DIO-hChR2(H134R)-eYFP-WPRE (referred to as AAV-ChR2-eYFP) was used; for the expression of only eYFP, pAAVEF1a-DIO-eYFP (referred to as AAV-eYFP) was used; and for the expression of mCherry and the red-shifted ChR2: rAAV2/Ef1a-DIOC1V1-(E122t/E162T)-TS-mCherry (referred to as AAV-rsChR2mCherry) was used. In order to retrogradely transfect neurons, we used AAV vectors (of the AAVrg serotype) that were obtained from Addgene. These AAVs lead to expression of the calcium indicator, GCaMP7s, under control of the synapsin promoter (i.e., pGP-AAVrgsyn-JGCaMP7s-WPRE; catalog \#104488) or the tdTomato fluorophore under control of the CAG promoter (i.e., AAVrg-CAG-tdTomato; cata$\log$ \#59462).

Radiotelemetry. Radiotelemeters (PAC-10, DSI) were used to continuously monitor cardiovascular parameters and locomotor activity during optogenetic stimulation in awake, freely-moving mice. Agtr1a-ChR2 mice and their littermate Agtrla-Cre controls were anesthetized using isoflurane and administered analgesic (Buprenex; $0.1 \mathrm{mg} \mathrm{kg}^{-1}$, s.c.). An incision $(\sim 1 \mathrm{~cm})$ was made on the midline of the ventral neck to expose the left carotid artery. Subsequently, a 1-cm-long segment of the carotid artery was separated from the vagus nerve using two silk sutures (size: 50 ); the cranial end of the segment was permanently ligated and the caudal end of the segment was temporally occluded. Next, the carotid artery was punctured and the catheter was slid into the artery lumen such that the tip extended into the aortic arch. The catheter was then secured in place using suture and the telemetry device was positioned subcutaneously, in the left flank region. Skin was closed with 5-0 monofilament suture, and mice were allowed to recover for at least $7 \mathrm{~d}$ before 
A

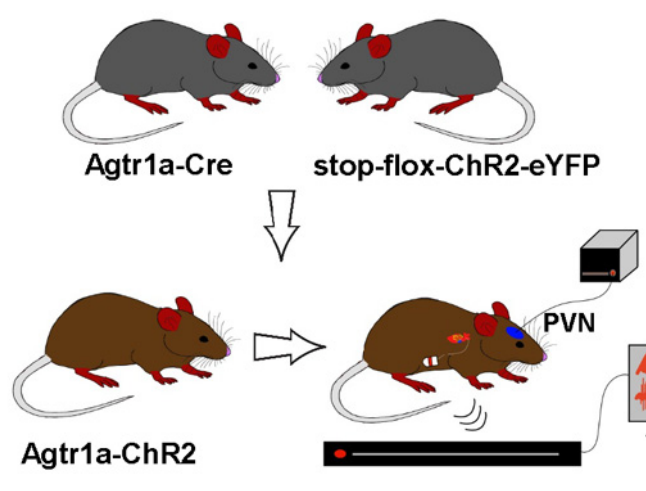

B

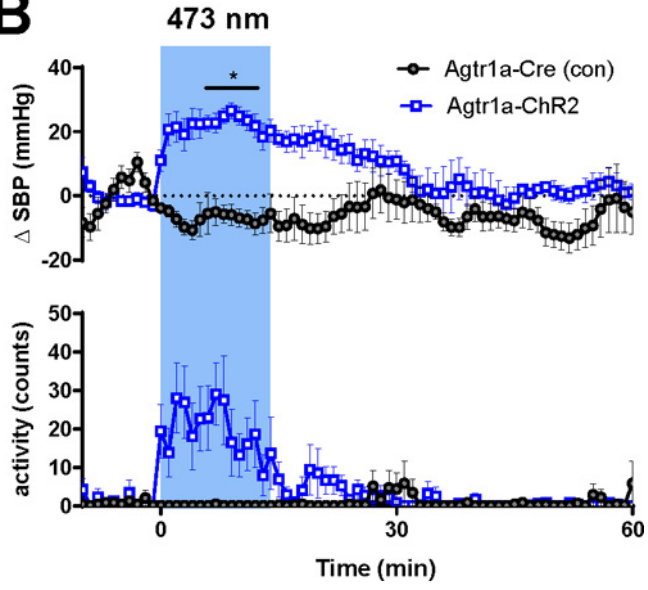

Figure 1. SBP and locomotor activity are robustly elevated when the PVN is optogenetically stimulated in mice with ChR2 expression directed to the Agtr7a gene. $A$, Schematic depicting the mouse line and experimental protocol. In this experiment, Agtr1a-ChR2 mice and littermate controls undergo optogenetic stimulation (10 mW; $15 \mathrm{~Hz} ; 5 \mathrm{~s}$ on/off; $15 \mathrm{~min}$ ) of Agtr1a neurons and afferents localized to the PVN. $\boldsymbol{B}$, Change in SBP and locomotor activity of mice before, during, and after optogenetic stimulation. Both SBP and locomotor activity were measured using the radiotelemetry transmitters. Error bars indicate SEM. Blue box represents period of optogenetic stimulation. ${ }^{*} p<0.05 . n=5$ per group.

undergoing stereotaxic surgery. During the study, cardiovascular parameters were continuously recorded and analyzed using Ponemah software (version 6.42, DSI).

Stereotaxic surgery. Stereotaxic surgery was performed to deliver AAVs or the retrograde neuronal tract tracer fluorogold (FG) into specific brain nuclei. We also used it to implant fiber optics targeting the PVN as previously described (de Kloet et al., 2017). Fiber optic implants allowed for optogenetic stimulation during cardiovascular recordings obtained in conscious freely moving mice or under general anesthesia. In preparation for aseptic stereotaxic surgery, mice were anesthetized using isoflurane and administered analgesic (Buprenex; $0.1 \mathrm{mg} \mathrm{kg}^{-1}$, $\mathrm{s}$. c.). To retrogradely label presympathetic neurons of the PVN, AgtrlatdTomato mice received bilateral stereotaxic microiontophoretic injections of FG ( $6 \mu \mathrm{A} 7 \mathrm{~s}$ pulses, $8 \mathrm{~min}$ ) into the rostral ventrolateral medulla (RVLM) using the following coordinates from $\lambda: 1.57 \mathrm{~mm}$ posterior, $\pm 1.3 \mathrm{~mm}$ lateral, and $5.07 \mathrm{~mm}$ ventral from the surface of the brain. These same coordinates were used to deliver AAVrg-syn-JGCaMP7sWPRE or AAVrg-CAG-tdTomato bilaterally into the RVLM using a picospritzer III (Parker). For AAV-mediated gene transfer to the PVN, Cre-inducible AAVs described above were injected bilaterally into the PVN using the following coordinates from bregma: AP: $\pm 0 \mathrm{~mm}$, ML: $\pm 0.25 \mathrm{~mm}, \mathrm{DV}:-4.75 \mathrm{~mm}$. For each AAV injection, the pipette was left in the ROI for 5 min to allow for diffusion of the AAVs (100-150 nl) into the brain. Mice administered FG were killed $7 \mathrm{~d}$ after the microiontophoretic injections to collect brains for neuroanatomical studies. Mice receiving AAV injections were allowed to recover for at least 3 weeks before subsequent procedures.

To retrogradely label PVN presympathetic neurons of male rats, rhodamine-labeled microspheres (Lumaflor) were unilaterally injected into the RVLM as previously described (Sonner et al., 2011). A stereotaxic apparatus was used to pressure inject $200 \mathrm{nl}$ of the tracer into the RVLM (starting from bregma: AP: $-12 \mathrm{~mm}, \mathrm{ML}: \pm 2 \mathrm{~mm}, \mathrm{DV}:-8 \mathrm{~mm}$ ). In general, RVLM injection sites were contained within the caudal pole of the facial nucleus to $\sim 1 \mathrm{~mm}$ more caudal and were ventrally located with respect to the nucleus ambiguus. The location of the tracer was verified histologically (Sonner et al., 2011). Rats were used 3-5 d after surgery.

RNAscope ISH and immunohistochemistry. In order to collect tissue for neuroanatomical studies, mice were anesthetized with pentobarbital (50 $\mathrm{mg} \mathrm{kg}^{-1}$, i.p.) and perfused transcardially with RNase free-isotonic saline followed by $4 \%$ PFA. Brains were then postfixed for $\sim 4 \mathrm{~h}$, after which they were stored in RNase-free 30\% sucrose for up to 1 week before further processing. For RNAscope ISH, the PVN (from bregma; $-0.22 \mathrm{~mm}$ to $-1.22 \mathrm{~mm}$ ) was sectioned at $20 \mu \mathrm{m}$ into 6 serial sections using a Leica CM3050 S cryostat (Leica Microsystems). Sections were immediately mounted onto Fisherbrand SuperFrost Plus Gold
Microscope Slides (Thermo Fisher Scientific). After air-drying at room temperature for 20-30 min, slides were dipped in $\mathrm{EtOH}$, again allowed to dry for $10-15 \mathrm{~min}$ and then stored at $-80^{\circ} \mathrm{C}$ until further processing. For immunohistochemical labeling of FG, mouse brains were sectioned at $30 \mu \mathrm{m}$ into four serial sections and stored in cryoprotective solution at $-20^{\circ} \mathrm{C}$, until further processing.

RNAscope ISH was performed using the RNAscope V2 Multiplex Fluorescent Reagent Kit (Advanced Cell Diagnostics) as per the manufacturer's instructions with slight modification to the pretreatment procedure that allows for preservation of the reporter genes (i.e., tdTomato and/or eYFP), while still providing optimal mRNA signal. The probes used for these studies were as follows: Agtrla (Mm-Agtrla-O1; catalog \#481161), Crhr1 (Mm-Crhr1; catalog \#418011), DapB (Negative control probe-DapB; catalog \#310043); Ubc (Mm-Ubc; catalog \#310771). Upon completion of the ISH for Agtrla that is depicted in Figure 1, slides were immediately coverslipped using Prolong Gold Antifade Mountant (Thermo Fisher Scientific). For labeling that is depicted in Figure 2, sections underwent immunohistochemical for GFP (used to amplify the eYFP signal) immediately following the ISH protocol.

Standard immunohistochemistry protocols were used to amplify FG or eYFP signal (de Kloet et al., 2017). Primary antibodies and dilutions used are as follows: GFP (Invitrogen [A10262]; 1:1000) and FG (Millipore [AB153]; 1:1000). Secondary antibodies were purchased from Jackson ImmunoResearch Laboratories, raised in donkey, and used at a 1:500 dilution. Briefly, brain sections were rinsed then incubated first in blocking solution ( $2 \%$ normal donkey serum and $0.2 \%$ Triton $\mathrm{X}$ in $50 \mathrm{~mm} \mathrm{KPBS}$ ) for $2 \mathrm{~h}$ at $25^{\circ} \mathrm{C}$ and then in the primary antibody (diluted in blocking solution) for $18 \mathrm{~h}$ at $4^{\circ} \mathrm{C}$. Sections were again rinsed $5 \times 5 \mathrm{~min}(50 \mathrm{~mm} \mathrm{KPBS})$ before incubation in the secondary antibody in blocking solution for $2 \mathrm{~h}$ at $25^{\circ} \mathrm{C}$. After a final series of rinses, slides were allowed to air dry and then coverslipped using Prolong Gold Antifade Mountant.

Image capture and processing. Images were captured and processed using Axiovision 4.8.2 software and a Zeiss AxioImager fluorescent Apotome microscope. Using the Apotome, $z$ stacks of the proteins and mRNAs of interest were captured at $20 \times$ magnification throughout the PVN using neuroanatomical landmarks (Franklin and Paxinos, 2008). An average of 10 optical sections were collected per $z$ stack $(1 \mu \mathrm{m}$ between $z$ steps), and these were used to generate projection images depicted in Figure 3. For ISH experiments, sections hybridized with the probes of interest (Agtrla or Crhr1) were used to determine the exposure time and image processing required to provide optimal visualization of RNA signal. As described in detail by de Kloet et al. (2016), these same parameters were then used to assess background fluorescence in sections hybridized with the negative control probe (DapB). Importantly, using these exposure times and image processing 
A

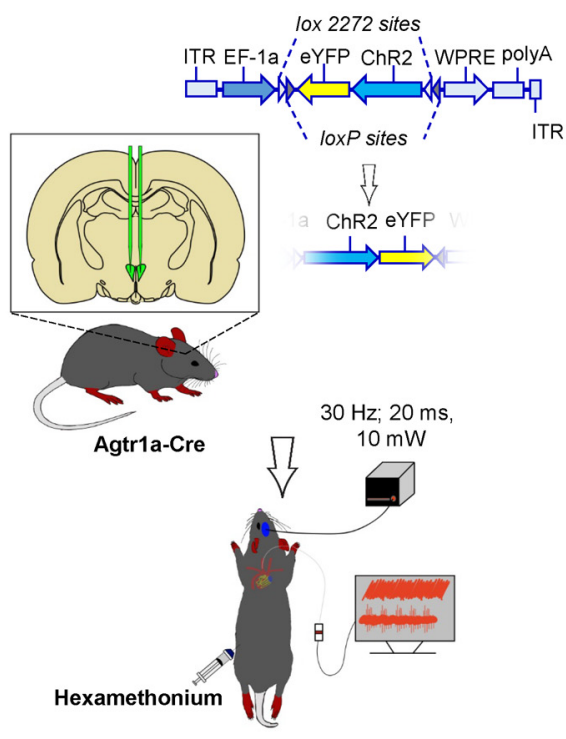

B

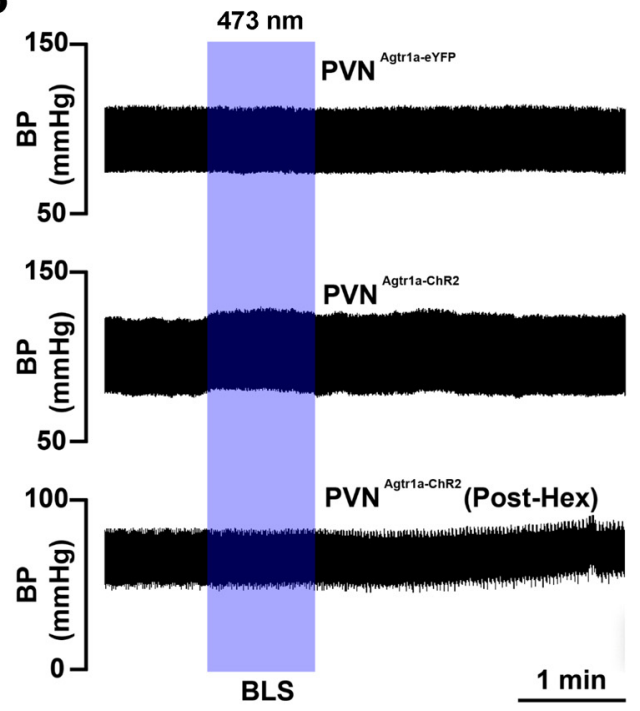

C

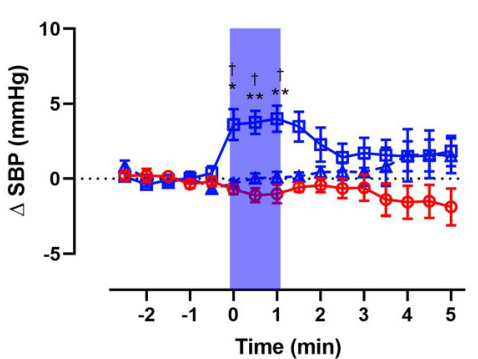

D
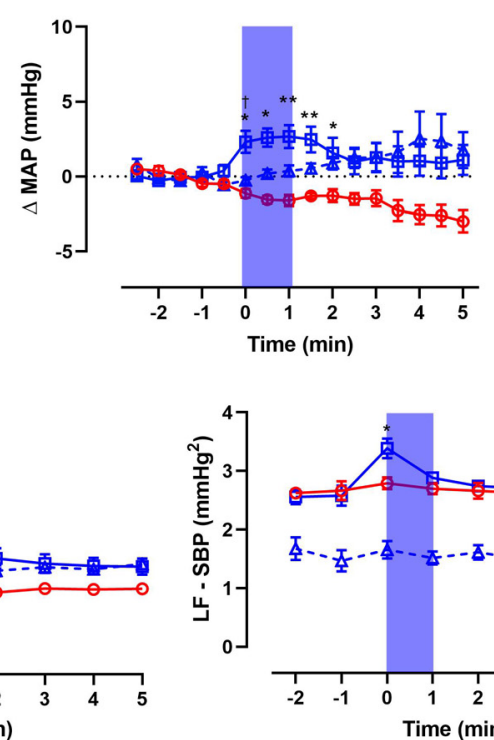

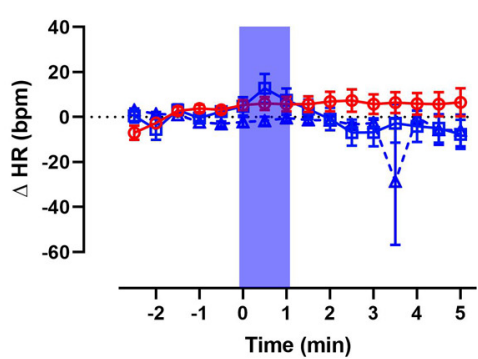

- PVN ${ }^{\text {Agtr1a-eYFP }}$

世 PVN ${ }^{\text {Agtr1a-ChR2 }}$

-A. PVN ${ }^{\text {Agtr1a-ChR2 }}$ (Post-Hex)
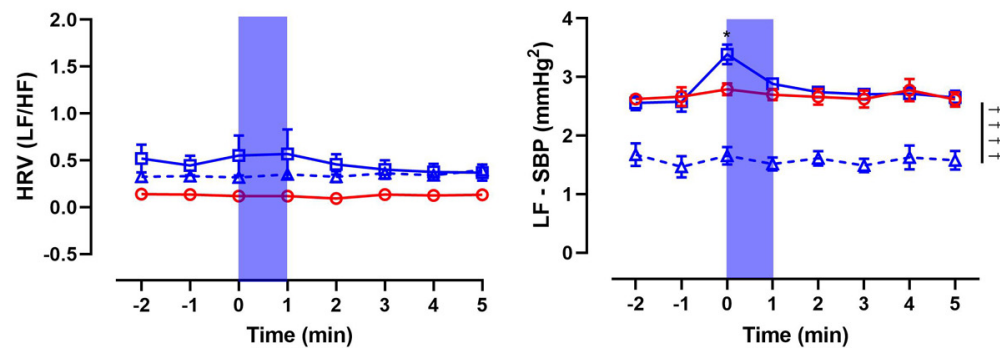

Figure 2. Optogenetic stimulation of PVN ${ }^{\mathrm{Agtr} 1 \mathrm{a}}$ elicits sympathetically mediated increases in blood pressure. $A$, Schematic depicting the mouse line and experimental protocol. In this experiment, Agtr1a-Cre mice received a Cre-inducible AAV-ChR2-eYFP into the PVN. Following recovery, PVNN ${ }^{\text {Agtrla }}$ were optogenetically stimulated $(10 \mathrm{~mW} ; 20 \mathrm{~ms}$ pulse width; $30 \mathrm{~Hz} ; 1 \mathrm{~min})$ while cardiovascular parameters were recorded via a Millar catheter inserted into the left carotid artery. B, Representative pulsatile arterial blood pressure traces following blue laser stimulation (BLS) in PVN ${ }^{A g t r 1-e Y F P}$ mice, PVN ${ }^{A g t r 1 a-C h R 2}$ mice, or PVN ${ }^{A g t r 1 a-C h R 2 ~}$ mice following the systemic administration of hexamethonium ( $30 \mathrm{mg} / \mathrm{kg}$, i.p.). C, Group means demonstrating the change in SBP (left), mean arterial pressure (MAP; middle), and heart rate (HR; right). D. Group means demonstrating the change in heart rate variability (left; HRV - ratio of the LF domain over the HF domain) and the LF domain of SBP variability (right; LF - SBP). Error bars indicate SEM. ${ }^{*} p<0.05{ }^{* * *} p<0.05$; two-way ANOVA followed by Tukey's post for PVN ${ }^{\text {Agtrla-eYFP }}$ versus PVN ${ }^{\text {Agtrla-ChR2 }}$. ${ }^{+} p<0.05$; two-way ANOVA followed by Tukey's post for PVN ${ }^{\text {Agtrla-ChR2 }}$ versus PVN ${ }^{\text {Agtrla-ChR2 }}$ (Post-Hex), $n=6:$ PVN $^{\text {Agtrla-eYFP }}, n=11$ : PVN ${ }^{\text {Agtrla-ChR2 }}, n=10$ : PVN ${ }^{\text {Agtrla-ChR2 }}$ (Post-Hex).

parameters, there was minimal or no fluorescence in sections hybridized with the negative control probe. All final figures were then prepared using Adobe Photoshop 2020, and the brightness and contrast were adjusted to provide optimal visualization.

Slice preparation. Experimental Agtrla-Cre mice for electrophysiological and in vitro $\mathrm{Ca}^{2+}$ imaging studies underwent stereotactic surgery (described above) at the University of Florida to deliver the AAVs described above bilaterally into the RVLM and PVN. After surgical recovery, they were transported via courier service (Optimize Courier) to Georgia State University for use in electrophysiological and/or in vitro $\mathrm{Ca}^{2+}$ imaging studies that were conducted $\sim 8-12$ weeks after stereotactic surgery.

On the day of the experiment, mice and rats were anesthetized with pentobarbital $\left(50 \mathrm{mg} \mathrm{kg}^{-1}\right.$, i.p.) and then perfused transcardially with 30 $\mathrm{ml}$ of ice-cold aCSF solution with $\mathrm{NaCl}$ replaced by equal-osmol sucrose.
This sucrose aCSF solution contained (in $\mathrm{mm}$ ): 200 sucrose, $2.5 \mathrm{KCl}, 1$ $\mathrm{MgSO}_{4}, 26 \mathrm{NaHCO}_{3}, 1,25 \mathrm{NaH}_{2} \mathrm{PO}_{4}, 20 \mathrm{D}$-glucose, 0.4 ascorbic acid, and $2.0 \mathrm{CaCl}_{2}, \mathrm{pH} 7.2,300-305 \mathrm{mOsmol} 1^{-1}$. The animal was then rapidly decapitated, and the brain was subsequently removed, mounted in the chamber of a vibrotome with superglue (Leica VT1200s, Leica Microsystems), and submerged in the same sucrose solution and bubbled constantly with $95 \% \mathrm{O}_{2} / 5 \% \mathrm{CO}_{2}$. Slices were cut at $240 \mu \mathrm{m}$ thickness and placed in a holding chamber containing aCSF bubbled with $95 \% \mathrm{O}_{2} / 5 \% \mathrm{CO}_{2}$. The aCSF is identical in composition to the sucrose solution, but with $200 \mathrm{~mm}$ sucrose replaced by $119 \mathrm{~mm} \mathrm{NaCl}$. The slice chamber was warmed using a water bath at $32^{\circ} \mathrm{C}$ for $20 \mathrm{~min}$ before placement at room temperature.

Simultaneous imaging and electrophysiology. Coronal hypothalamic slices were placed into a specimen chamber on the stage of a Nikon Eclipse FN1 microscope and perfused constantly $(\sim 3 \mathrm{ml} / \mathrm{min})$ with 

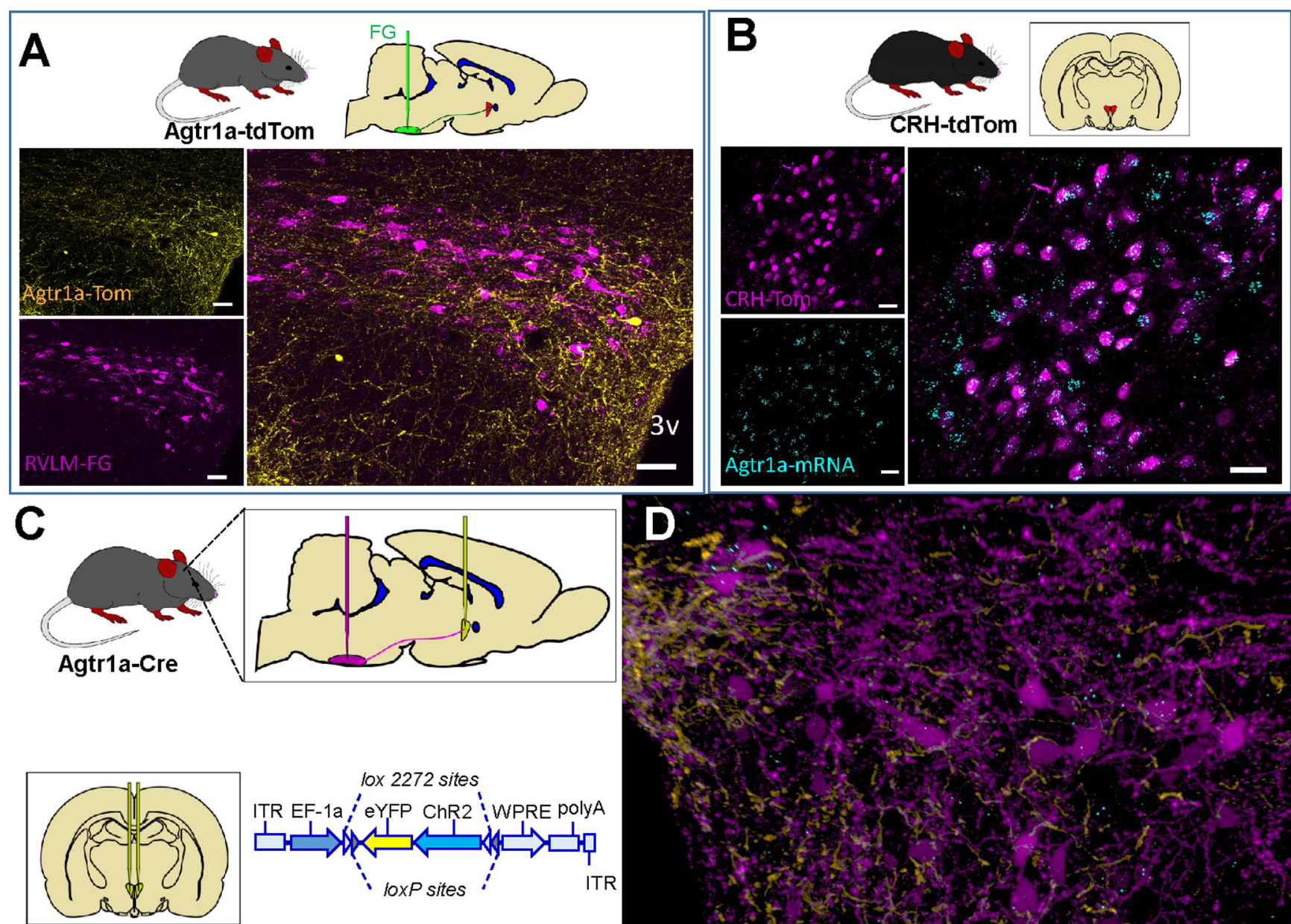

IOX 2272 sites
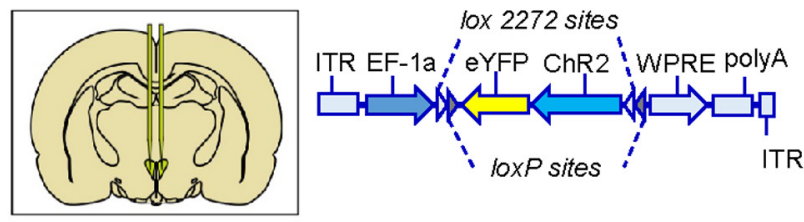

$3 v$
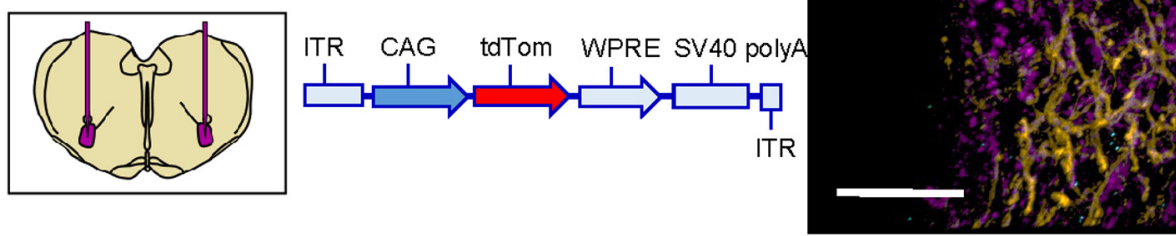

\section{.}


Whole-cell current-clamp recordings were obtained from fluorescently labeled PVN neurons using pipettes $(2.5-4 \mathrm{M} \Omega$ ) pulled from borosilicate glass (O.D. $1.5 \mathrm{~mm}$ ) using a P-97 flaming/brown horizontal micropipette puller (Sutter Instruments). The pipette internal solution consisted of the following (in mM): $135 \mathrm{KMeSO}_{4}, 8 \mathrm{NaCl}, 10$ HEPES, $2 \mathrm{Mg}$-ATP, $0.3 \mathrm{Na}$-GTP, 6 phosphocreatine, 0.2 EGTA with pH 7.2-7.3 and $285-295 \mathrm{mOsmol}\left(\mathrm{kg} \mathrm{H}_{2} \mathrm{O}\right)^{-1}$. The liquid junction potential for the $\mathrm{KMeSO}_{4}$ internal was $\sim-10 \mathrm{mV}$ and was not corrected. For currentclamp recordings, traces were obtained with an Axopatch 200B amplifier (Molecular Devices) and digitized using an Axon 1440B Digitizer (Molecular Devices) at $10 \mathrm{kHz}$ on a Dell desktop computer running Clampex 10 software (Molecular Devices). Data were discarded if series resistance exceeded a $20 \%$ change over the course of the recording.

Anesthetized assessment of blood pressure in response to optogenetic manipulations. Agtrla-Cre male mice received stereotactic injections of the Cre-inducible AAV-ChR2-eYFP or AAV-eYFP into the PVN as described above. Three to 4 weeks later, mice were anesthetized using isoflurane and a Millar catheter (model SPR1000, Millar) was implanted into the aortic arch by way of the carotid artery using a similar procedure as described above for the implantation of telemetry devices. After catheterization, mice underwent stereotactic surgery to lower a fiber optic into the PVN for optical stimulation using the following coordinates from bregma: AP: $\pm 0 \mathrm{~mm}, \mathrm{ML} \pm 0.25 \mathrm{~mm}, \mathrm{DV}-3.8 \mathrm{~mm}$.

In order to collect cardiovascular data, the Millar catheter was connected to a PowerLab signal transduction unit (AD Instruments). Blood pressure and heart rate data were sampled/recorded at $1 \mathrm{kHz}$ and analyzed using Labchart8 software (AD Instruments). To test the effect of optical stimulation of Agtrla neurons of the PVN on blood pressure, mice were optically stimulated with $473 \mathrm{~nm}$ blue light for $60 \mathrm{~s}(10 \mathrm{~mW}$ output; $20 \mathrm{~ms}$ pulse width; $30 \mathrm{~Hz}$ ). Mice then received injections of hexamethonium (30 mg/kg, i.p.) or saline vehicle. Once blood pressure again stabilized ( $\sim 15-20 \mathrm{~min}$ after the injections), mice were again subjected to optical stimulation using the same parameters. Blood pressure data were condensed into $30 \mathrm{~s}$ bins to perform statistical analyses and to generate the figures.

Anesthetized assessment of blood pressure in response to pharmacological injections. Age-matched C57BL/6J male mice were anesthetized using isoflurane and a Millar catheter was implanted into the aortic arch as described above. Following catheterization, a glass micropipette (borosilicate glass with filament, O.D. $1.5 \mathrm{~mm}$, I.D. $0.86 \mathrm{~mm}$, Sutter Instrument) was lowered into the PVN using a stereotaxic frame with the following coordinates from bregma: AP: $\pm 0 \mathrm{~mm}, \mathrm{ML} \pm 0.25 \mathrm{~mm}$, DV $-4.75 \mathrm{~mm}$. The PVN was then microinjected with either Astressin at 50, 100, $200 \mu \mathrm{M}$ (Astressin, Tocris Bioscience), or vehicle (10\% acetic acid in $\mathrm{H}_{2} \mathrm{O}$, pH 7.4). Microinjections were conducted at different orders in all mice, alternating between the right and the left $\mathrm{PVN}$ with a $30 \mathrm{~min}$ interval between each microinjection. The volume of all injections was $\sim 100 \mathrm{nl}$. At the end of all microinjections, mice received hexamethonium $(30 \mathrm{mg} / \mathrm{kg}$, i.p.) and were then subjected to a PVN microinjection of Astressin $(200 \mu \mathrm{M} / 100 \mathrm{nl})$. Blood pressure was sampled at $30 \mathrm{~s}$ every $60 \mathrm{~s}$ for $2 \mathrm{~min}$ and $10 \mathrm{~min}$ before and following microinjections, respectively.

In a different set of experiments, Agtr1a-Cre mice received stereotactic injections of the Cre-inducible AAV-ChR2-eYFP into the PVN, and following 3 weeks of recovery mice were anesthetized and a Millar catheter (model SPR1000, Millar) was implanted into the aortic arch as described above. Subsequently, a dual optical injector cannula (Optical Injector, Doric) was lowered above the PVN, allowing microinjections and optogenetic stimulation within the same site while blood pressure was simultaneously recorded. Either vehicle ( $10 \%$ acetic acid, $\mathrm{pH} 7.4$ ) or Astressin $(200 \mu \mathrm{M})$ was microinjected, and pulses of $473 \mathrm{~nm}$ laser light (10 mW output; $20 \mathrm{~ms}$ pulse width; $30 \mathrm{~Hz} ; 1 \mathrm{~min}$ ) were delivered $5 \mathrm{~min}$ following microinjections. Blood pressure was sampled at $30 \mathrm{~s}$ every $60 \mathrm{~s}$ for $2 \mathrm{~min}$ and $5 \mathrm{~min}$ before and following optical stimulation, respectively.

Spectral analysis of heart rate and SBP variability. Heart rate variability (HRV) was analyzed using a Heart Rate Variability Analysis Software provided in Labchart8 (AD Instruments), whereas SBP variability was analyzed using a fast Fourier transform spectral variation in
SBP using Labchart 8. Briefly, HRV and SBP variability were sampled at $1 \mathrm{~min}$ bins before and following optogenetic stimulation, and the frequency bands were as follows: very low frequency (LF), LF, and high frequency (HF) at $0-0.15 \mathrm{~Hz}, 0.15-1.5 \mathrm{~Hz}$, and $1.5-5 \mathrm{~Hz}$, respectively. $\mathrm{HRV}$ was expressed as an LF/HF ratio, which is a surrogate clinical marker of sympatho-vagal balance to the heart (Tasić et al., 2017). The LF domain of SBP variability indicates the level of sympathetic vasoconstrictor activity (deBoer et al., 1987; Madwed et al., 1989).

Statistics. All electrophysiological traces were analyzed in ClampFit 10.7 (Molecular Devices) and Igor Pro (Wavemetrics). Calcium data were analyzed in ImageJ and Igor Pro. Statistics were performed with Prism GraphPad. The following statistical tests were used: paired-samples $t$ test (see Figs. 4C, 6Civ, 9E), and two-way ANOVA with Tukey's post hoc test (see Figs. $5 E, 7 F, G, 8 B$ ). All reported data are represented as mean \pm SEM.

Telemetric recordings of blood pressure and activity in awake freelymoving mice were performed and analyzed using Ponemah software (DSI), while cardiovascular parameters obtained from anesthetized mice were analyzed in Labchart 8 (AD Instruments). For all cardiovascular parameters, two-way ANOVAs with Tukey's multiple comparison tests were performed using GraphPad (see Figs. $1 B, 2 C, D, 9 B, C, 10 C$ ). Data are expressed as mean \pm SEM.

\section{Results}

\section{In vivo optogenetic stimulation of the $\mathrm{PVN}$ elicits robust elevations in blood pressure when $\mathrm{ChR} 2$ expression is directed to the Agtr1a gene}

The PVN coordinates the release of neuroendocrine factors with alterations in autonomic outflow to maintain blood pressure at levels optimal for survival (Sladek et al., 2015). Prior research heavily implicates Agtrla(s) in the regulation of these processes. In particular, Ang-II induced activation of Agtrla(s) evokes changes in neuronal activity associated with activation of the HPA and HPT axes, augmented sympathetic outflow, vasopressin release, and elevated blood pressure (Bains et al., 1992; Jezova et al., 1998; Q. Zhu et al., 2005; Y. F. Li et al., 2006; de Kloet et al., 2017). To begin to elucidate the precise signaling mechanisms associating Agtrla(s), neuronal activity, and cardiovascular function within the PVN, we bred mice homozygous for the Agtrla-Cre knock-in gene to mice heterozygous for the knock-in of the stopflox-ChR2-eYFP gene at the ubiquitous ROSA26 locus. This breeding scheme resulted in offspring with expression of the light-sensitive cation ion channel, ChR2, directed to the Agtrla gene or littermate controls harboring only the Agtrla-Cre gene (Fig. 1A). These two groups of male mice were implanted with radiotelemetry devices and chronic dwelling fiber optics targeting the PVN, thereby allowing for continuous monitoring of cardiovascular parameters in conscious freely moving subjects during optogenetic activation of $\mathrm{PVN}^{\text {Agtrla }}$. After surgical recovery and habituation to the tethering procedures, fiber optics were connected to a $473 \mathrm{~nm}$ laser light source and mice underwent optical stimulation of the PVN (10 $\mathrm{mW} ; 15 \mathrm{~Hz}, 5 \mathrm{~s}$ on/off; $15 \mathrm{~min}$ ). In the absence of optical stimulation, control mice and Agtr1a-ChR2 mice exhibited similar SBPs (Agtr1a-Cre $=107.2 \pm 2.5 \mathrm{mmHg} ; \quad$ Agtr1a-ChR2 $=101 \pm 2.5$ $\left.\mathrm{mmHg} ; t_{(8)}=1.643 ; p=0.1389\right)$ and locomotor activity (AgtrlaCre $=0.70 \pm 0.49$ counts/min; Agtrla-ChR2 $=1.16 \pm 0.93$ counts/ $\left.\min ; t_{(8)}=0.44 ; p=0.67\right)$. As illustrated in Figure $1 B$, relative to controls harboring only the Agtrla-Cre gene, optical stimulation of the PVN in Agtr1a-ChR2 mice elicited pronounced elevations in SBP (main effects of genotype $\left[F_{(1,8)}=12.3 ; p=0.008\right]$ and time $\left[F_{(4.834,38.67)}=2.92 ; p=0.026\right]$ and a time $\times$ genotype interaction $\left.\left[F_{(70,560)}=4.32 ; p<0.0001\right]\right)$ and locomotor activity (main effects of genotype $\left[F_{(1,8)}=9.815 ; p=0.014\right]$ and time $\left[F_{(3.5,28)}=3.5 ; p=0.023\right]$ and a time $\times$ genotype interaction $\left.\left[F_{(70,560)}=4.18 ; p<0.0001\right]\right)$ that 


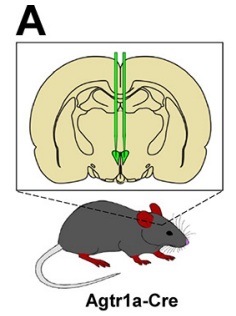

B

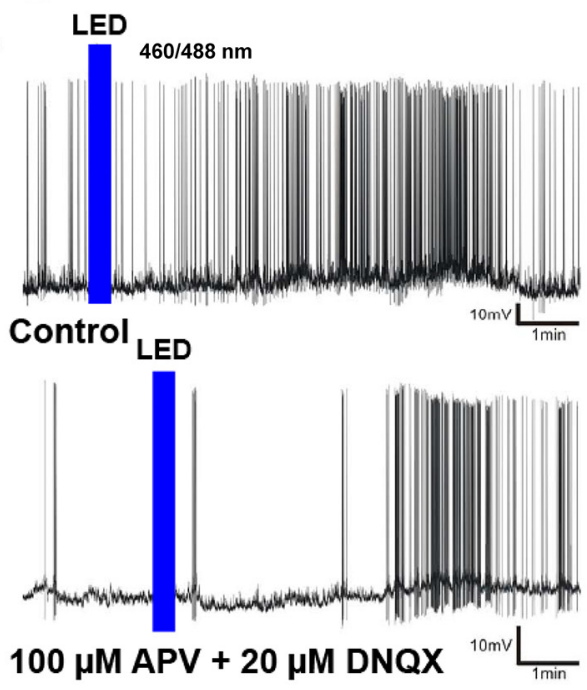

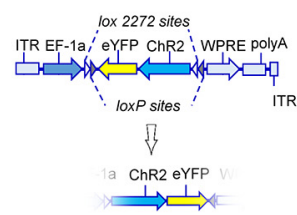

C

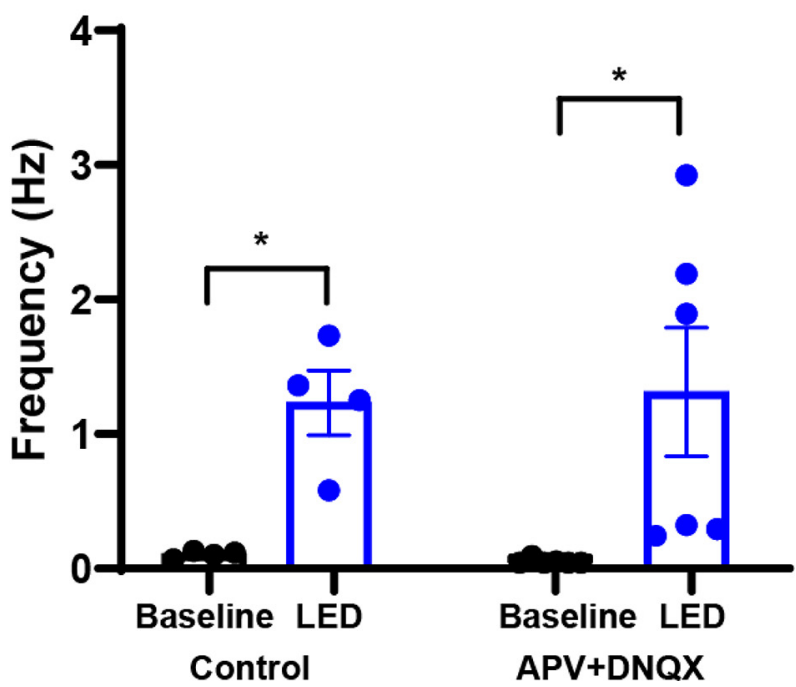

Figure 4. Selective optogenetic excitation of PVN ${ }^{\text {Agtrla }}$ evokes a delayed firing response from putative presympathetic neurons. $A$, Schematic of the AAV-mediated gene transfer approach used to direct expression of eYFP and ChR2 to PVN ${ }^{\text {Agtra }}$. B, Current-clamp recordings of putative presympathetic neurons. LED stimulation evokes increased firing frequency under control conditions (top) and in the presence of DNQX/APV (bottom). C, Summary data showing the increased firing of putative presympathetic neurons before and after LED-induced excitation of PVN ${ }^{\mathrm{Agtrl} a}\left({ }^{*} p<0.05, n=\right.$ 4 cells from 2 animals). The LED-evoked firing increase persisted in the presence of DNQX/APV ( ${ }^{*} p<0.05, n=6$ cells from 3 animals)). ${ }^{*} p<0.05$. Error bars indicate SEM.

persisted throughout the period of optical stimulation and, in the case of blood pressure, extended several minutes thereafter.

\section{Specific in vivo optogenetic activation of $\mathrm{PVN}^{\mathrm{Agtr1a}}$ increases blood pressure, an effect that is abolished by ganglionic blockade}

The previous experiment established that Cre-Lox-mediated direction of ChR2 to the Agtr1a gene results in altered cardiovascular function when blue light is pulsed into the PVN; however, there are caveats to consider. In particular, Cre recombination that occurs with our breeding scheme results in production of ChR2 in all cells that express the Agtrla gene throughout the course of development, which includes neurons residing outside the PVN. In this regard, the subfornical organ and the median preoptic nucleus are brain regions that express Agtrla(s) that send axonal projections into the PVN (Bains et al., 1992; Z. Li and Ferguson, 1993; Krause et al., 2011; Leib et al., 2017; Frazier et al., 2021). Thus, the optogenetic approach implemented in the prior experiment likely excites these axonal projections, as well as the soma of PVN ${ }^{\text {Agtrla }}$. To circumvent this caveat and further delineate the specific role that PVN ${ }^{\text {Agtrla }}$ play in cardiovascular function, we stereotaxically administered Cre-inducible AAVs (AAV2-eYFP or AAV2-ChR2-eYFP) into the PVN of Agtr1aCre male mice (Fig. 2A). This produced mice with ChR2 expression specifically within PVN ${ }^{\text {Agtrla }}$ or controls expressing only the eYFP fluorophore. After 3-4 weeks of recovery, mice were anesthetized and a Millar catheter (model SPR1000) was inserted into the carotid artery to record cardiovascular parameters. After the catheter was secured, mice were placed into a stereotaxic apparatus and a microcraniotomy was performed dorsal to the PVN. Subsequently, a fiber optic connected to a laser light source was slowly lowered into the PVN, and cardiovascular responses to pulses of $473 \mathrm{~nm}$ light were recorded (10 mW output; $20 \mathrm{~ms}$ pulse width; $30 \mathrm{~Hz} ; 1 \mathrm{~min})$. As shown in Figure $2 B$, $C$, optical stimulation had no effect on cardiovascular parameters when given to Agtrla-Cre mice administered the control virus producing only eYFP. In contrast, pulsing $473 \mathrm{~nm}$ light into the PVN of Agtr1a-Cre mice given AAV-ChR2-eYFP reliably produced a significant increase in blood pressure that was sustained until the cessation of illumination (Fig. $2 B, C$; $\mathrm{PVN}^{\text {Agtrla-eYFP }} ;-1.0 \pm$ $0.6 \mathrm{mmHg}, \mathrm{PVN}^{\text {Agtrla-ChR2 }} ; 4.0 \pm 0.9 \mathrm{mmHg}$ at $1 \mathrm{~min}$, main effects of genotype $\left[F_{(15,240)}=2.2 ; p=0.0064\right]$ and time $\left[F_{(1,240)}=\right.$ 58.15; $p<0.0001], n=6-11)$. However, no effects were observed on heart rate (Fig. $2 C ; \mathrm{PVN}^{\text {Agtr1a-eYFP }} 5.7 \pm 3.4$ bpm, PVN ${ }^{\text {Agtr1a-ChR2 }} ; 7.9 \pm 5.2 \mathrm{bpm}$ at $1 \mathrm{~min}\left[F_{(15,240)}=0.81\right.$; $p=0.6693], n=6-11)$. While anesthesia may have blunted the cardiovascular response to optogenetic stimulation, these results indicate that the elevations in the blood pressure observed in the prior experiment cannot be solely attributed to concurrent increases in locomotor activity. As mentioned, the PVN contains neurosecretory and presympathetic neurons that influence cardiovascular function by controlling the release of endocrine factors into the systemic circulation or sympathetic nervous activity, respectively. To gain insight into mechanisms coupling excitation of PVN ${ }^{\text {Agtrla }}$ to altered cardiovascular function, we combined systemic administration of the nicotinic 
A

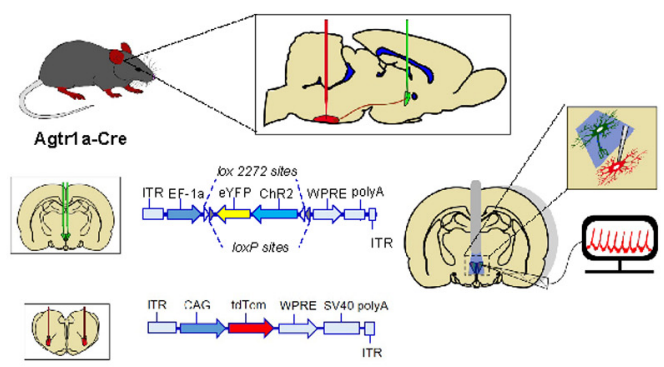

C
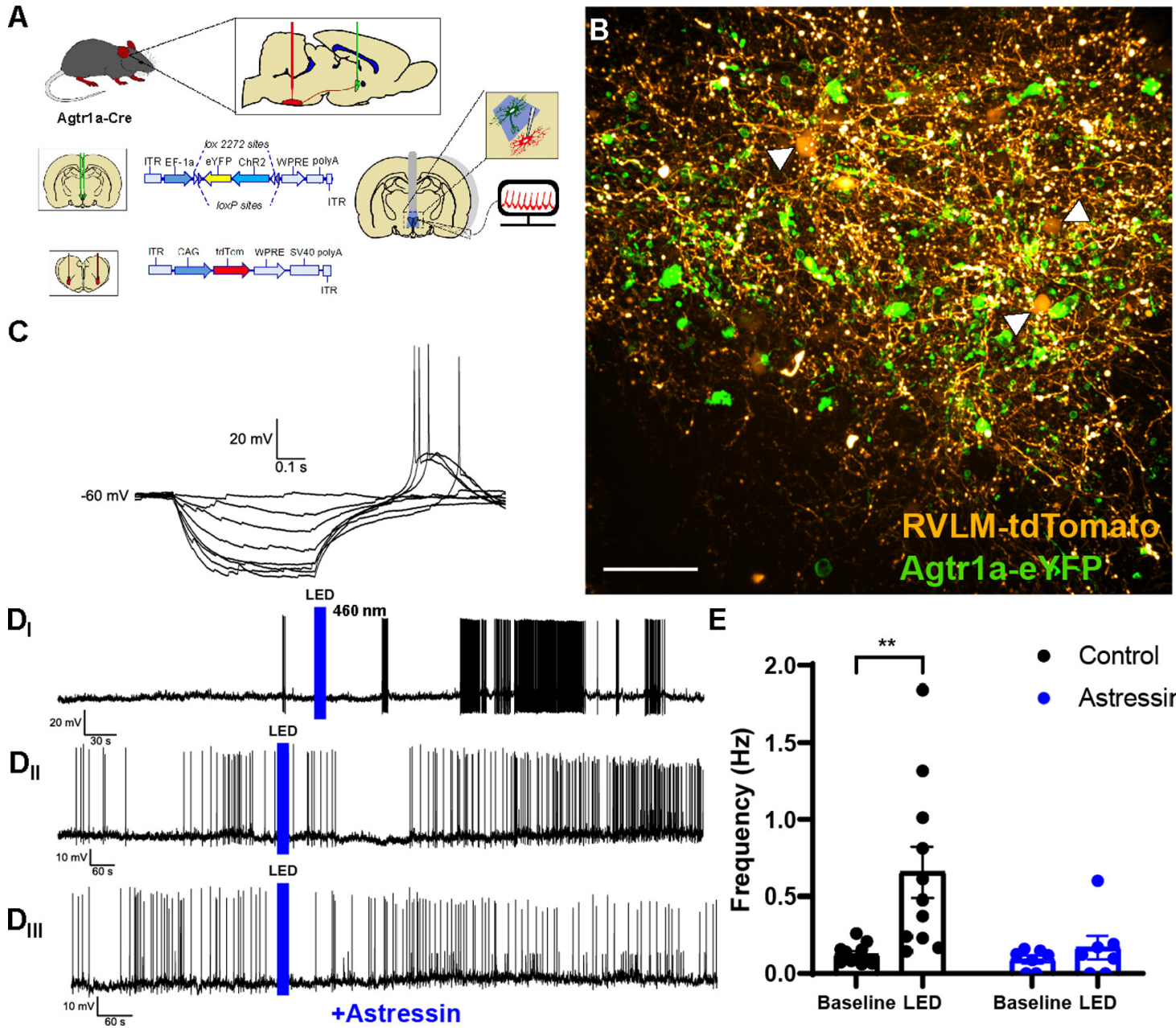

E

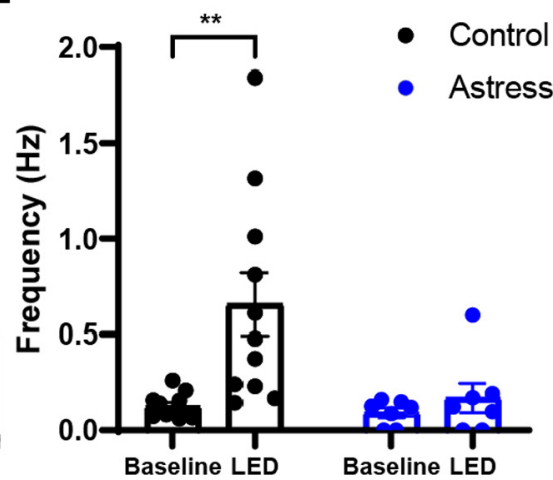

Figure 5. LED stimulation of PVN ${ }^{A g t r l a}$ increases firing frequency of PVN neurons retrogradely labeled from the RVLM, which can be abrogated by Astressin. $A$, Schematic of the AAV injections used to direct the expression of eYFP-ChR2 to PVN ${ }^{\text {Agtrla }}$ while also driving retrograde expression of tdTomato in PVN neurons projecting to the RVLM. $\boldsymbol{B}$, Confocal image of coronal slice through the PVN depicting RVLM-projecting neurons labeled with tdTomato (yellow) and PVN ${ }^{\text {Agtrla }}$ expressing eYFP and ChR2 (green). Scale bar, $50 \mu \mathrm{m}$. C, Current-clamp recording of the I-V relationship of a RVLM-projecting neuron. The presence of a low-threshold transient depolarization confirms that the cell is consistent with electrophysiological properties attributed to presympathetic neurons of the PVN. $\boldsymbol{D}_{i}$, Current-clamp recording of a patch-clamped RVLM-projecting neuron. LED stimulation of PVN ${ }^{\text {Agtrla }}$ causes a delayed upregulation in firing of RVLM-projecting neurons. $\boldsymbol{D}_{i i}$ Current-clamp recording from another RVLM-projecting neuron that also exhibits a delayed firing response to LED stimulation of PVN ${ }^{\text {Agtrla }}$ that is suppressed in the presence of Astressin $\left(\boldsymbol{D}_{i i i,} 0.5 \mu \mathrm{M}\right)$. $\boldsymbol{E}$, Summary data of firing frequency from recordings of RVLM-projecting neurons before and after the LED stimulation. LED stimulation of PVNAgtrla significantly increased the firing frequency of RVLM-projecting neurons ( ${ }^{* *} p<0.01$, two-way ANOVA followed by Tukey's post hoc test, $n=11$ cells from 5 animals). The LED stimulation of PVN ${ }^{\text {Agtria }}$ did not significantly increase the firing frequency of RVLMprojecting neurons in the presence of Astressin ( $p>0.05$, two-way ANOVA followed by Tukey's post hoc test $n=7$ cells from 3 animals). Error bars indicate SEM.

receptor antagonist, hexamethonium (30 mg/kg, i.p.), with in vivo optogenetics to determine whether altered autonomic function contributes to the increase in blood pressure that accompanies the excitation of $\mathrm{PVN}^{\text {Agtrla }}$. Figure $2 B, C$ shows that the cardiovascular responses previously observed with optogenetic excitation of $\mathrm{PVN}^{\text {Agtrla }}$ were abolished in the presence of hexamethonium (Fig. 2C; $\mathrm{PVN}^{\text {Agtrla-ChR2 }} ; 4.0 \pm 0.9 \mathrm{mmHg}, \mathrm{PVN}^{\text {Agtrla-ChR2 }}$ (Post-Hex); $0.1 \pm 0.4 \mathrm{mmHg}$ at $1 \mathrm{~min}$, main effects of treatment $\left[F_{(15,302)}=1.94\right.$; $p=0.0197]$ and time $\left[F_{(1,302)}=18.26 ; p<0.0001\right], n=10$ or 11$)$. To further establish that the increases in blood pressure are sympathetically mediated, we conducted heart rate variability and SBP variability analyses (Fig. 2D). Following blue light stimulation, no changes were observed in heart rate variability, a surrogate indicator of sympatho-vagal balance to the heart (Fig. $2 D$; PVN ${ }^{\text {Agtrla-eYFP }} ; 0.1 \pm 0.1$, $\mathrm{PVN}^{\text {Agtrla-ChR2 }} ; 0.6 \pm 0.3$ at $1 \mathrm{~min}\left[F_{(7,120)}=0.15 ; p=0.9931\right], n=6-$ 11). This suggests that the selective excitation of PVN ${ }^{\text {Agtrla }}$ does not affect heart rate nor the autonomic drive to the heart. Intriguingly, optical stimulation of PVN ${ }^{\text {Agtrla }}$ produced a significant increase in the LF domain of SBP variability, an indicator of sympathetic vasoconstrictor activity (Fig. $2 D$; PVN ${ }^{\text {Agtrla-eYFP }} ; 2.8 \pm 0.1 \mathrm{mmHg}^{2}$, $\mathrm{PVN}^{\text {Agtrla-ChR2 }} ; 3.4 \pm 0.2 \mathrm{mmHg}^{2}\left[F_{(7,120)}=2.76 ; p=0.0107\right], n=6$ 11). Changes in the LF domain of SBP variability were attenuated by the systemic administration of hexamethonium (Fig. 2D; $\mathrm{PVN}^{\text {Agtrla-ChR2 }} ; 3.4 \pm 0.2 \mathrm{mmHg}^{2}, \quad \mathrm{PVN}^{\text {Agtrla-ChR2 }}$ (Post-Hex); $1.7 \pm 0.2 \mathrm{mmHg}^{2} \quad\left[F_{(7,152)}=2.31 ; p=0.0287\right], n=10$ or 11$)$. Furthermore, the administration of hexamethonium decreased the baseline of the LF domain of SBP variability, suggesting that hexamethonium does indeed block autonomic outflow to the vasculature (Fig. 2D). Together, these results suggest that the increased blood pressure that follows selective excitation of PVN ${ }^{\text {Agtrla }}$ is dependent on increased sympathetic outflow to the vasculature.

Fibers arising from $\mathrm{PVN}^{\text {Agtr1a }}$ make appositions onto neighboring neurons that express mRNA for the CRH1 receptor and send direct projections to the RVLM Follow-up experiments probed the neuroanatomical basis underlying the cardiovascular effects observed with optogenetic activation of $\mathrm{PVN}^{\mathrm{Agtrla}}$. A recent study determined that optogenetic 
excitation of neurons in the PVN that have direct axonal projections to the RVLM increases sympathetic nervous system activity and blood pressure (Koba et al., 2018). This prior study, in conjunction with our present results, suggests that optogenetic activation of PVN ${ }^{\text {Agtrla }}$ may increase blood pressure by exciting RVLM-projecting neurons within the PVN. In particular, it is possible that RVLM-projecting neurons synthesize Agtrla(s) and the increased blood pressure that is observed with optogenetic stimulation is the result of their direct excitation. To confirm or refute this possibility, mice with the red fluorescent protein variant, tdTomato, directed to the Agtrla gene were iontophoretically administered the retrograde neuronal tract-tracer, FG, bilaterally into the RVLM (Fig. 3A). Seven days later, Agtr1a-tdTomato mice were perfused and brains were processed for FG immunohistochemistry to evaluate whether PVN neurons with identified projections to the RVLM synthesize Agtrla(s) as indicated by colocalization with tdTomato. As shown in Figure $3 A$, neurons with direct projections to the RVLM, here, deemed presympathetic, mostly populated the caudal $(\approx-1.06 \mathrm{~mm}$ from bregma) region of the PVN (Franklin and Paxinos, 2008). As can be seen, somatic expression of tdTomato in this region was scant and did not colocalize with FG, suggesting that Agtr1a(s) are not present on presympathetic neurons in the PVN.

In contrast to the caudal region, the medial region $(\approx-0.82$ $\mathrm{mm}$ from bregma) of the PVN is densely populated with AgtrlatdTomato labeling (de Kloet et al., 2017). The medial PVN contains neurosecretory parvocellular neurons that synthesize CRH and initiate activation of the HPA axis. Subsequent experiments evaluated whether such neurons express Agtrla(s). Toward this end, mice with the tdTomato expression directed to the $C R H$ gene (CRH-tdTomato) were perfused and coronal sections through the PVN were processed for RNAscope ISH for Agtrla mRNA. Figure $3 B$ depicts tdTomato and blue puncta, indicative of labeling for CRH-synthesizing neurons and mRNA coding for Agtrla(s), respectively. Quantitative analysis revealed that the majority of tdTomato-labeled neurons colocalized with Agtrla mRNA (176 of 215 CRH-tdTomato cells express Agtrla mRNA; $n=3$ mice), thereby demonstrating extensive expression of Agtrla(s) on CRH neurons of the PVN. Together, these results suggest that $\mathrm{PVN}^{\text {Agtrla }}$ are not presympathetic neurons that project to the RVLM but, rather, are CRH-synthesizing neurons that coupled their excitation to changes in autonomic outflow that elevate blood pressure.

Given that prior studies revealed a local intra-PVN cross-talk among peptidergic neurosecretory and presympathetic neurons (Son et al., 2013; Jiang et al., 2018), we next sought to determine whether PVN ${ }^{\text {Agtrla }}$, which synthesize $\mathrm{CRH}$, have processes that come into close proximity with presympathetic neurons that express CRHR1(s). To visualize soma and efferents arising from $\mathrm{PVN}^{\text {Agtrla }}$, we delivered a Cre-inducible anterograde viral tracer (AAV-ChR2-eYFP) into the PVN of Agtr1a-Cre male mice. The same mice were delivered a pan-neuronal retrograde virus (AAVrg-CAG-tdTomato) into the RVLM to label presympathetic neurons with tdTomato (Fig. 3C). After 3-4 weeks of recovery, mice were perfused and brains were processed for immunohistochemistry and RNAscope ISH for eYFP and CRH 1 receptor (CRH1R) mRNA, respectively. As shown in Figure $3 D-F, \mathrm{PVN}^{\text {Agtr1a }}$ send a dense plexus of fibers (yellow) to the caudal PVN ( $\approx-1.06 \mathrm{~mm}$ from bregma). These fibers are in close proximity to neurons retrogradely labeled with tdTomato (magenta). Efforts to identify neurons colabeled with eYFP and tdTomato were unsuccessful, consistent with our prior results demonstrating that presympathetic neurons in the PVN are devoid of the Agtrla. A subset of these RVLM-projecting neurons exhibited colocalization of tdTomato and CRHR1 mRNA (magenta soma with blue puncta; Fig. 3E,F). Quantitative analysis revealed that $57 \%$ ( 181 of 316 neurons; $n=4$ mice) of RVLMprojecting neurons expressed mRNA for the CRHR1. Interestingly, a subset ( $43 \%$ or 152 of 351 neurons; $n=4$ mice) of PVN $^{\text {Agtrla }}$ were also found to synthesize CRHR1 mRNA. Collectively, these results demonstrate that, within the PVN, the Agtrla is robustly expressed on $\mathrm{CRH}$ neurons, but presympathetic neurons do not produce this receptor but, rather, synthesize CRHR1(s). The implication is that excitation of $\mathrm{PVN}^{\text {Agtrla }}$ may trigger the release of $\mathrm{CRH}$, which stimulates CRHR1(s) on neighboring presympathetic neurons to alter sympathetic outflow and cardiovascular function.

\section{Ex vivo optogenetic stimulation of $\mathrm{PVN}^{\text {Agtr1a }}$ evokes excitation of presympathetic neurons that is mediated by CRHR1(s)}

To probe for functional connectivity between $\mathrm{PVN}^{\text {Agtr1a }}$ and presympathetic neurons, we used an ex vivo approach that combined optogenetics, patch-clamp electrophysiology, and $\mathrm{Ca}^{2+}$ imaging. As a first strategy, we delivered a Cre-inducible AAV that expresses ChR2 and eYFP (AAV-ChR2-eYFP) into the PVN of Agtr1a-Cre mice (Fig. 4A). This allowed selective excitation of $\mathrm{PVN}^{\text {Agtr1a }}$ with ex vivo optogenetics. To determine whether optogenetic excitation of PVN ${ }^{\text {Agtrla }}$ affects the activity of presympathetic neurons, we obtained patch-clamp recordings from parvocellular neurons that were in the vicinity of ChR2-eYFPexpressing fibers originating from $\mathrm{PVN}^{\text {Agtrla }}$, but that were themselves devoid of fluorescent protein expression. The majority of these neurons ( $n=8$ cells from 7 animals) exhibited a low-threshold spike and lacked a transient outward rectification, electrophysiological characteristics often exhibited by presympathetic neurons (Luther and Tasker, 2000; Stern, 2001). As shown in Figure $4 B$, optogenetic stimulation of PVN ${ }^{\text {Agtrla }}$ (LED 460/ $488 \mathrm{~nm}$; 20-30 pulse train, $50 \mathrm{~ms}$ pulse, $100 \mathrm{~ms}$ interval) consistently evoked a delayed $(195.0 \pm 19.4 \mathrm{~s})$ excitatory response in putative presympathetic PVN neurons, which resulted in a significant increase in firing discharge under control conditions (Fig. $4 C ; t_{(3)}=4.73, p=0.018$, paired $t$ test).

These results suggest that excitation of $\mathrm{PVN}^{\text {Agtrla }}$ spurs neighboring neurons in the PVN to fire action potentials and subsequent experiments investigated the basis for this coupling. We previously determined that PVN ${ }^{\text {Agtrla }}$ neurons express GLUT2 mRNA, a marker for glutamate, the major excitatory neurotransmitter in the hypothalamus (van den Pol, 1982; de Kloet et al., 2017). Accordingly, we repeated these experiments in the presence of the NMDA and AMPA glutamate receptor antagonists, APV $(100 \mu \mathrm{M})$ and DNQX $(20 \mu \mathrm{M})$, respectively, to evaluate whether the concomitant excitation of putative presympathetic neurons was mediated by glutamate. As shown in Figure $4 C$, application of APV and DNQX had no effect on the increased action potentials exhibited by parvocellular neurons subsequent to optogenetic excitation of $\mathrm{PVN}^{\text {Agtrla }}$. That is, similar to what we observed in the previous experiment, optogenetic stimulation consistently evoked a delayed (mean delay: $145.0 \pm 41 \mathrm{~s}$ ) excitatory response in putative presympathetic neurons in the presence of the synaptic blockers (Fig. $4 C ; t_{(5)}=2.64, p=0.046$, paired $t$ test). Together, these results indicate that activation $\mathrm{PVN}^{\text {Agtr1a }}$ evokes an excitatory response in putative presympathetic neurons, and that this interpopulation cross-talk displays a slow time course, and is not mediated by glutamate, a fast-acting excitatory neurotransmitter. 
Based on these initial studies and our neuroanatomical results showing the robust expression of Agtrla(s) on CRH neurons and the intriguing presence of CRHR1(s) on presympathetic neurons, we set up to directly test the hypothesis that presympathetic neurons are responsive to excitation of $\mathrm{PVN}^{\text {Agtr 1a }}$, and that this cross-talk is mediated by a slow acting neuropeptide, namely, CRH. Toward this end, we again delivered a Cre-inducible AAV-ChR2-eYFP into the PVN of Agtrla-Cre mice, but this time, we also bilaterally administered into the RVLM a pan neuronal viral construct (AAVrg-CAG-tdTomato) that promotes retrograde expression of tdTomato (Fig. 5A). This approach allows for simultaneous optogenetic excitation of PVN ${ }^{\text {Agtrla }}$ with patch-clamp recordings from known presympathetic neurons identified with the presence of tdTomato. First, we obtained patch-clamp recordings from neurons retrogradely labeled with tdTomato in slices through the PVN that also contained soma and fibers arising from $\mathrm{PVN}^{\text {Agtrla }}$ (Fig. 5B). As expected, we found that eYFP and tdTomato labeled separate populations of neurons in the PVN and tdTomato-expressing neurons exhibited electrophysiological characteristics indicative of having direct projections to the RVLM (Fig. 5C) (Stern, 2001). Optogenetic excitation of PVN ${ }^{\text {Agtrla }}$ (LED $460 \mathrm{~nm}$; 30 pulse train, $50 \mathrm{~ms}$ pulse, $100 \mathrm{~ms}$ interval) consistently evoked a delayed $(157.4 \pm 16.1 \mathrm{~s})$ excitatory response in identified presympathetic neurons, that resulted in a significant increase in firing discharge $(\sim 430 \%$ change; Fig. $5 C D i, E ;\left[F_{(1,32)}=5.70, p=0.003\right]$, two-way ANOVA followed by Tukey's post hoc test, $n=11$ cells from 5 animals). This effect was not dependent on the baseline degree of activity of presympathetic neurons (Pearson $r^{2}=0.08, p=0.4$ ). Importantly, the increased activity of presympathetic neurons that was evoked by optogenetic excitation of PVN ${ }^{\text {Agtr1a }}$ was abrogated when slices were preincubated with the CRH receptor antagonist, Astressin $\left(0.5 \mu \mathrm{M}\right.$; Fig. 5CDii, iii,E; $\left[F_{(1,32)}=5.70\right.$, $p=0.96$ ], two-way ANOVA followed by Tukey's post hoc test, $n$ $=7$ cells from 3 animals).

Prior work from our group determined that within the PVN, dendritically released arginine vasopressin (AVP) evokes excitatory responses in presympathetic neurons by stimulating $\mathrm{V} 1 \mathrm{a}$ receptors (Son et al., 2013). Therefore, it is possible that V1a receptors act as an intermediary between the activation of PVN $^{\text {Agtr1a }}$ and concomitant excitation of presympathetic neurons. To rule out this possibility, we repeated our ex vivo experiments in the presence of a V1a receptor antagonist, $[\beta$-mercapto$\beta, \beta$-cyclopentamethylenepropionyl1, O-me-Tyr2, Arg8]-vasopres$\sin (\mathrm{V} 1 \mathrm{aR}-\mathrm{A} ; 1 \mu \mathrm{M})$. We found that the increase in presympathetic neuronal firing activity following optogenetic excitation of $\mathrm{PVN}^{\text {Agtrla }}$ persisted in the presence of the V1aR-A (baseline: $0.14 \pm 0.1 \mathrm{~Hz}$; LED 460: $0.77 \pm 0.2 \mathrm{~Hz}, p<0.05, n=3$ ). Together, these results support the overall notion that activity-dependent release of CRH from PVN ${ }^{\text {Agtrla }}$ evokes a CRHR1-mediated excitatory response in presympathetic neurons.

\section{Ex vivo optogenetic stimulation of $\mathrm{PVN}^{\text {Agtr1a }}$ evokes a CRHR1-mediated increase in intracellular $\mathrm{Ca}^{2+}$ levels in presympathetic neurons}

Follow-up experiments combined ex vivo optogenetics and ex vivo calcium imaging as a complementary strategy to further support the functional cross-talk between $\mathrm{PVN}^{\text {Agtr1a }}$ and presympathetic neurons. Accordingly, we delivered an AAV (AAVrsChR2-mCherry) producing red-shifted ChR2 (C1V1) and red fluorescent protein (mCherry) into the PVN of Agtr1a-Cre mice (Fig. 6A). These male mice were also bilaterally administered into the RVLM a viral construct that allows retrograde expression of the ultrasensitive fluorescent protein calcium sensor, GCaMP7s, under the control of the synapsin promoter (Fig. $6 A$ ). Eight to 10 weeks later, coronal slices through the PVN revealed efficacious transfection of GCaMP7s (range $=1-5$ neurons/slice), particularly in the caudal region of the nucleus $(\approx-1.06 \mathrm{~mm}$ from bregma; Fig. $6 B)$. To first validate this approach, we bath-applied NMDA $(50 \mu \mathrm{M})$ and observed a robust and synchronous increase in intracellular calcium $\left(\left[\mathrm{Ca}^{2+}\right]\right.$ ic) in several presympathetic neurons within the slice (Fig. $6 \mathrm{Ci}$ $i v ; t_{(7)}=4.82, p=0.006$, paired $t$ test $n=10$ cells from 2 animals). Additionally, in a few cases, we patched presympathetic neurons expressing GCaMP7s and found clear increases in $\left[\mathrm{Ca}^{2+}\right]$ ic following bursts of action potentials evoked by current injection through the patch pipette (Fig. 6Di-iv). These results support efficient retrograde expression and sensitivity of the genetically encoded $\mathrm{Ca}^{2+}$ sensor in presympathetic neurons. Next, we used the same viral and $\mathrm{Ca}^{2+}$ imaging approaches to evaluate whether excitation of PVN ${ }^{\text {Agtrla }}$ affected $\left[\mathrm{Ca}^{2+}\right]$ ic of presympathetic neurons in the PVN (Fig. $7 A$ ). First, we validated that PVN ${ }^{\text {Agtr1a }}$ transfected with rsChR2 responded to pulses of $525 \mathrm{~nm}$ of light by patch clamping PVN neurons labeled with mCherry (Fig. 7B). These neurons lacked both a low threshold spike and a delayed outward rectification (Fig. 7B, inset) (Luther and Tasker, 2000). Stimulation of $\mathrm{PVN}^{\text {Agtrla }}$ with varying protocols using the $525 \mathrm{~nm}$ LED excitation reliably and consistently evoked firing activity in the patched neurons (Fig. 7C). These results demonstrate that $\mathrm{PVN}^{\text {Agtr1a }}$ exhibit electrophysiological characteristics of neurosecretory parvocellular neurons and validate our ability to optogenetically excite $\mathrm{PVN}^{\text {Agtr1a }}$ using a red-shifted opsin. Optogenetic excitation of PVN ${ }^{\text {Agtrla }}$ (LED $525 \mathrm{~nm}$; 30 pulse train, $50 \mathrm{~ms}$ pulse, $100 \mathrm{~ms}$ interval) consistently evoked a delayed $(157.9 \pm 17.2 \mathrm{~s})$ increase in the frequency (Fig. $7 F ;\left[F_{(1,38)}=10.1\right.$, $p=0.001$ ], two-way ANOVA followed by Tukey's post hoc test, $n=15$ cells from 5 animals) and amplitude (Fig. $7 G ;\left[F_{(1,38)}=8.4\right.$, $p=0.0003]$, two-way ANOVA followed by Tukey's post hoc test, $n=5$ of 15 ) of $\left[\mathrm{Ca}^{2+}\right]$ ic in presympathetic neurons (Fig. 7Di-iii). The delay in the $\left[\mathrm{Ca}^{2+}\right]$ ic response was not different from that observed with spiking (see Fig. 5D, left, E). The responses were almost completely abolished when slices were preincubated with Astressin $(0.5 \mu \mathrm{M}$ and no change was observed for either frequency; Fig. $7 F ;\left[F_{(1,38)}=10.13, p=0.64\right]$, two-way ANOVA followed by Tukey's post hoc test, $n=6$ cells from 3 animals) or amplitude (Fig. $7 G ;\left[F_{(1,38)}=8.4, p=0.9\right]$, two-way ANOVA followed by Tukey's post hoc test, $n=6$ cells from 3 animals).

These results indicate that the activity of PVN ${ }^{\text {Agtrla }}$ is coupled to increased firing of presympathetic neurons via activation of CRHR1(s); however, whether stimulation of Agtrla(s) per se also elicits this interpopulation cross-talk was not evaluated. Consequently, follow-up experiments examined whether application of Ang-II, the endogenous ligand for Agtrla(s), evoked a similar $\mathrm{CRH}$-mediated increased firing of PVN presympathetic neurons. In order to visualize presympathetic neurons in the PVN, male rats were administered RetroBeads into the RVLM. Three to five days later, coronal sections were made through the PVN and patch-clamp recordings were obtained from identified presympathetic neurons before, during, and after bath application of Ang-II (Fig. 8A). Bath application of Ang-II (0.5 $\mu \mathrm{M}, 1 \mathrm{~min})$ significantly increased the firing frequency of presympathetic PVN neurons (Fig. $8 B ;\left[F_{(1,12)}=10.15, p=0.003\right]$, two-way ANOVA followed by Tukey's post hoc test, $n=4$ cells from 2 animals). Importantly, this increase was completely abolished when slices were preincubated in Astressin (0.5 $\mu \mathrm{M}$, Fig. $8 B$; $\left[F_{(1,12)}=10.15, p=0.99\right]$, two-way ANOVA followed by Tukey's post hoc test, $n=4$ cells from 2 
A
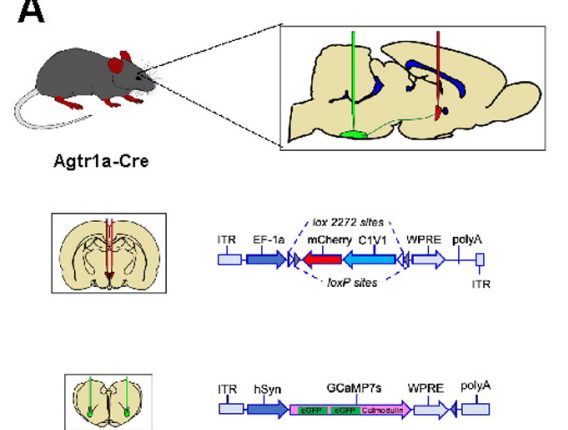

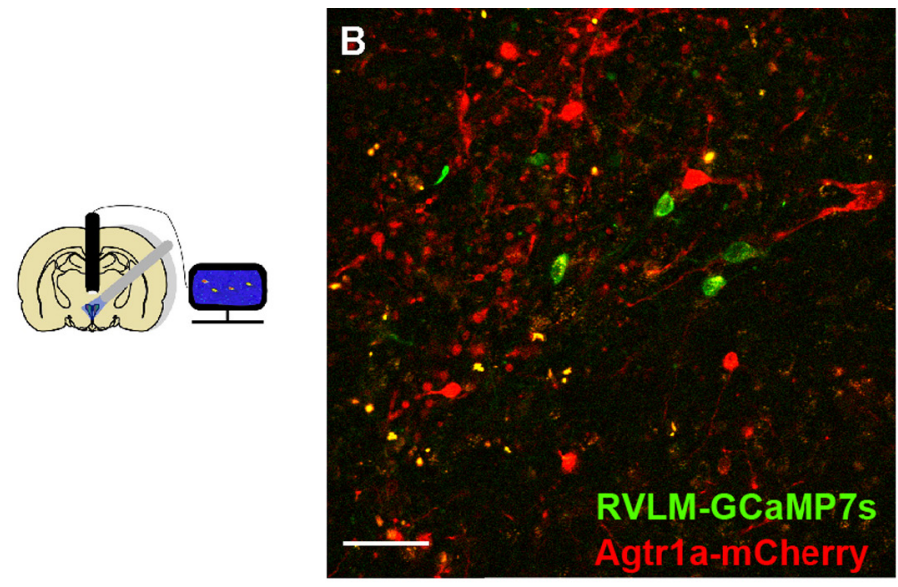

$\mathrm{C}_{\mathrm{iii}}$

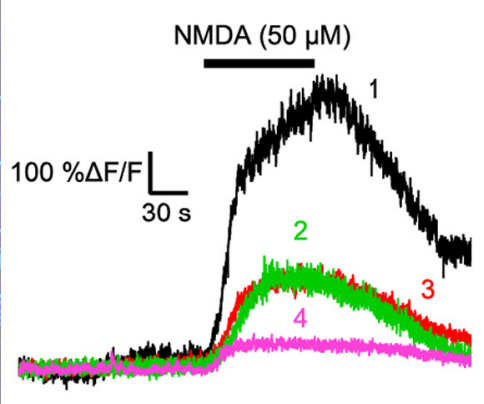

$\mathrm{C}_{\mathrm{iv}}$
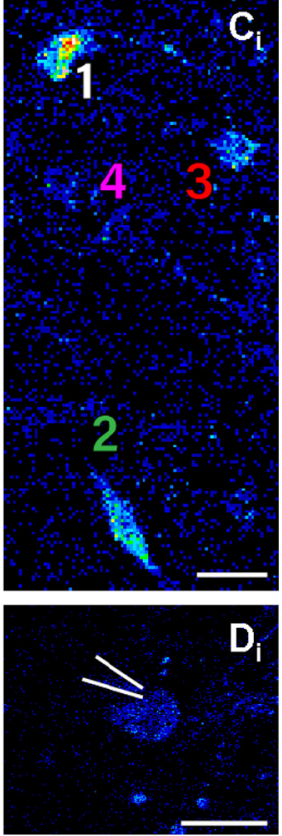
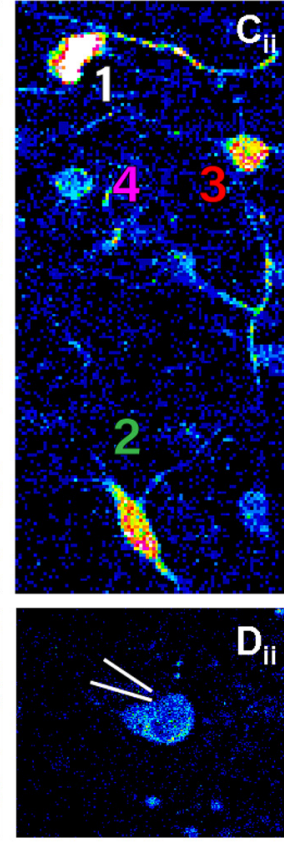

$D_{\text {iii }}$

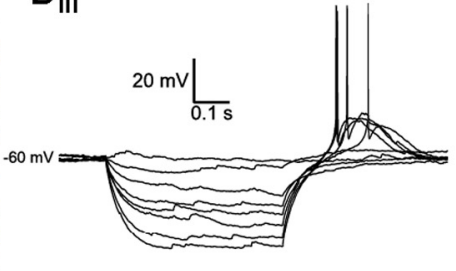

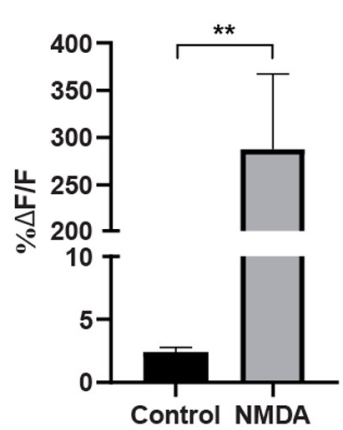

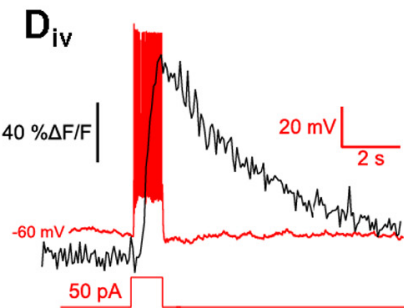

Figure 6. Characterization of GCaMP7s expression in PVN neurons that project to the RVLM. $\boldsymbol{A}$, Schematic of the AAV injections used to direct the expression of rsChR2-mCherry to PVN $N_{\text {Agtrla }}$ while also driving retrograde expression of GCaMP7s in PVN neurons projecting to the RVLM. Fluorescence intensity is used as a proxy for neuronal firing and can be simultaneously recorded from multiple neurons in a slice through the PVN. $\boldsymbol{B}$, Two-photon microscopy depicting a coronal section through the PVN with GCaMP7s (green) expression within RVLM-projecting neurons and rsChR2-mCherry (red) expression within PVN ${ }^{\text {Agtrla }}$. Scale bar, $50 \mu \mathrm{m}$. $\boldsymbol{C}$, Two-photon microscopy showing the fluorescence intensity of GCaMP7s within RVLM-projecting $\left(\boldsymbol{C}_{\boldsymbol{i}}\right)$ before and $\left(\boldsymbol{C}_{i i}\right)$ during NMDA $(50 \mu \mathrm{m})$ application. Scale bar, $25 \mu \mathrm{m}$. $\boldsymbol{C}_{i i i i}$ Corresponding measurements of $\% \Delta \mathrm{F} / \mathrm{F}$ changes in neurons from $\boldsymbol{C}_{i-i i}$ in response to a $50 \mu \mathrm{m}$ application of NMDA. $\boldsymbol{C}_{\boldsymbol{i v} \text {, }}$ Summary data of average peak $\% \Delta \mathrm{F} / \mathrm{F}$ changes in response to NMDA ( $p=0.006$, paired $t$ test, $n=10$ cells from 2 animals). $\boldsymbol{D}$, Individual GCaMP7s expressing neurons are patch-clamped and fluorescence is recorded $\left(\boldsymbol{D}_{\boldsymbol{i}}\right)$ before and $\left(\boldsymbol{D}_{i i}\right)$ during the peak increase after an injection of current. Scale bar, $25 \mu \mathrm{m} . n=2$ cells from 1 animals. $\boldsymbol{D}_{\text {iiii }}$, $I-V$ relationship in current-clamp mode of the neuron from $\boldsymbol{D}_{\boldsymbol{i}-i \text { i }}$. This cell exhibited the low-threshold depolarization that is indicative of PVN presympathetic neurons. $\boldsymbol{D}_{\boldsymbol{i v}}$. Current-clamp trace (red) and the corresponding change in GCaMP7s fluorescence (black) when current $(1 \mathrm{~s}, 50 \mathrm{pA})$ is injected into the neuron in $\boldsymbol{D}_{\text {i-ii. }}$. Error bars indicate SEM. ${ }^{* *} P<0.01$.

animals). Collectively, results from our ex vivo experiments support the notion that within the PVN, Ang-II activates Agtrla(s) expressed on $\mathrm{CRH}$ neurons, which evokes a delayed and indirect excitation of presympathetic neurons that is dependent on stimulation of CRH1R(s).

\section{In vivo blockade of $\mathrm{CRH}$ receptors in the $\mathrm{PVN}$ alters} cardiovascular function under basal conditions and during optogenetic excitation of PVN ${ }^{\text {Agtr1a }}$

The results from our anatomic and electrophysiological studies predict that excitation of $\mathrm{PVN}^{\text {Agtrla }}$ promotes the release of $\mathrm{CRH}$, which engages CRHR1(s) expressed on presympathetic neurons to augment sympathetic outflow and elevate blood pressure. Here, we conducted complementary in vivo and ex vivo studies to test the validity of this prediction. Initial experiments used WT male C57BL/6J mice to evaluate how administering varying doses of Astressin affects blood pressure. Toward this end, mice were anesthetized and a Millar catheter was implanted into the left common carotid artery to record cardiovascular parameters. Subsequently, a microcraniotomy was performed dorsal to the PVN, using a stereotaxic frame, and a glass micropipette was lowered into the PVN to perform unilateral microinjections $(100 \mathrm{nl})$ of either the vehicle ( $10 \%$ acetic acid, $\mathrm{pH}$ 7.4) or Astressin (50, 100, $200 \mu \mathrm{M})$. Before microinjections, there were no differences in baseline blood pressure among the groups (vehicle; 106.5 $\pm 9.2 \mathrm{mmHg}$, Astressin; $110.2 \pm 4.7$ $\mathrm{mmHg}, 110.3 \pm 8.5 \mathrm{mmHg}, 99.2 \pm 10.2 \mathrm{mmHg}$ for 50,100 , and $200 \mu \mathrm{M}$, respectively $\left[F_{(3,20)}=0.3775 ; p=0.7702\right], n=6$ per group). However, relative to microinjection of vehicle, Astressin induced a dose-dependent and transient depressor response in 


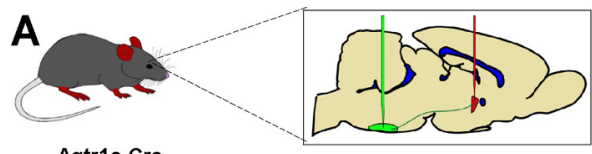

Agtr1a-Cre
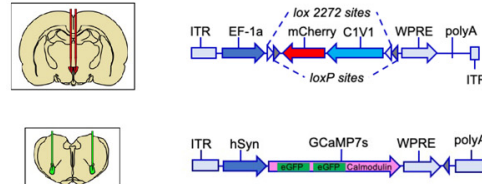

ITR hSYn GCaMP7s WPRE PolyA
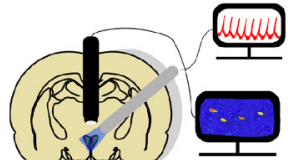

C

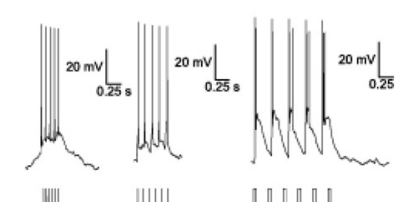

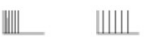

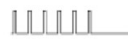

$1 \mathrm{~ms}$ pulse width $1 \mathrm{~ms}$ pulse width $10 \mathrm{~ms}$ pulse width
$50 \mathrm{~ms}$ interval $100 \mathrm{~ms}$ interval $250 \mathrm{~ms}$ interval
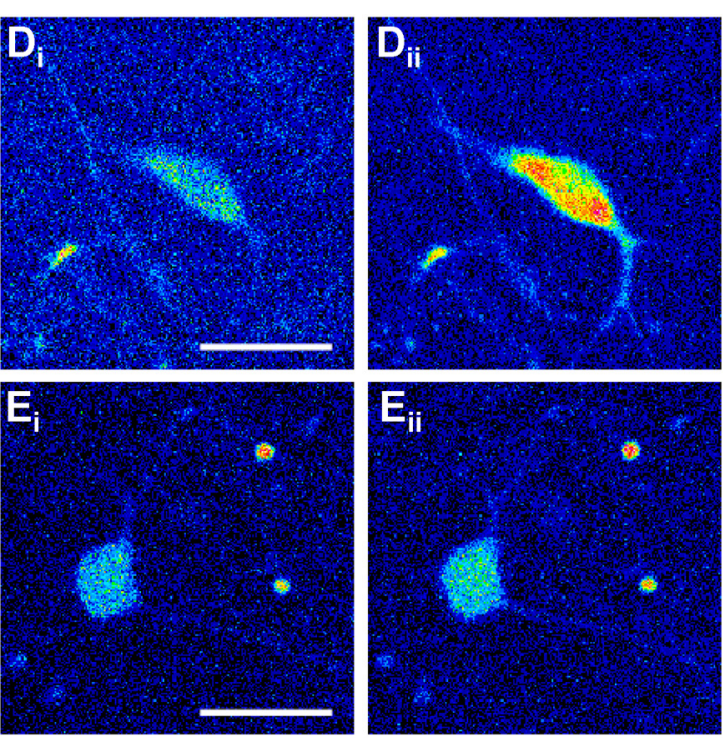

F

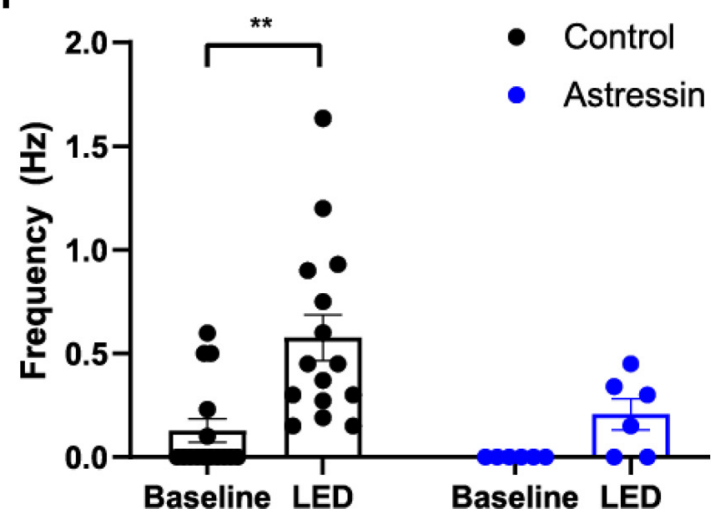

$D_{\text {iii }}$
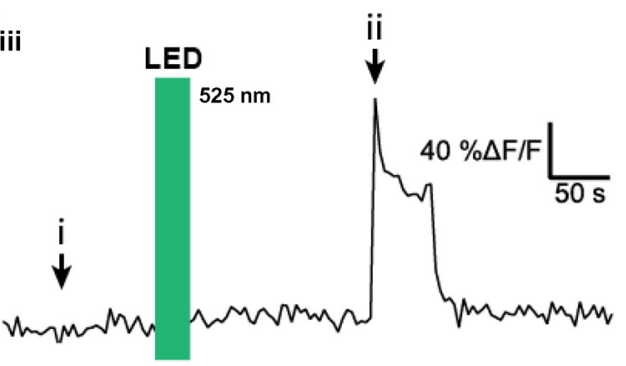

$E_{\text {iii }}$
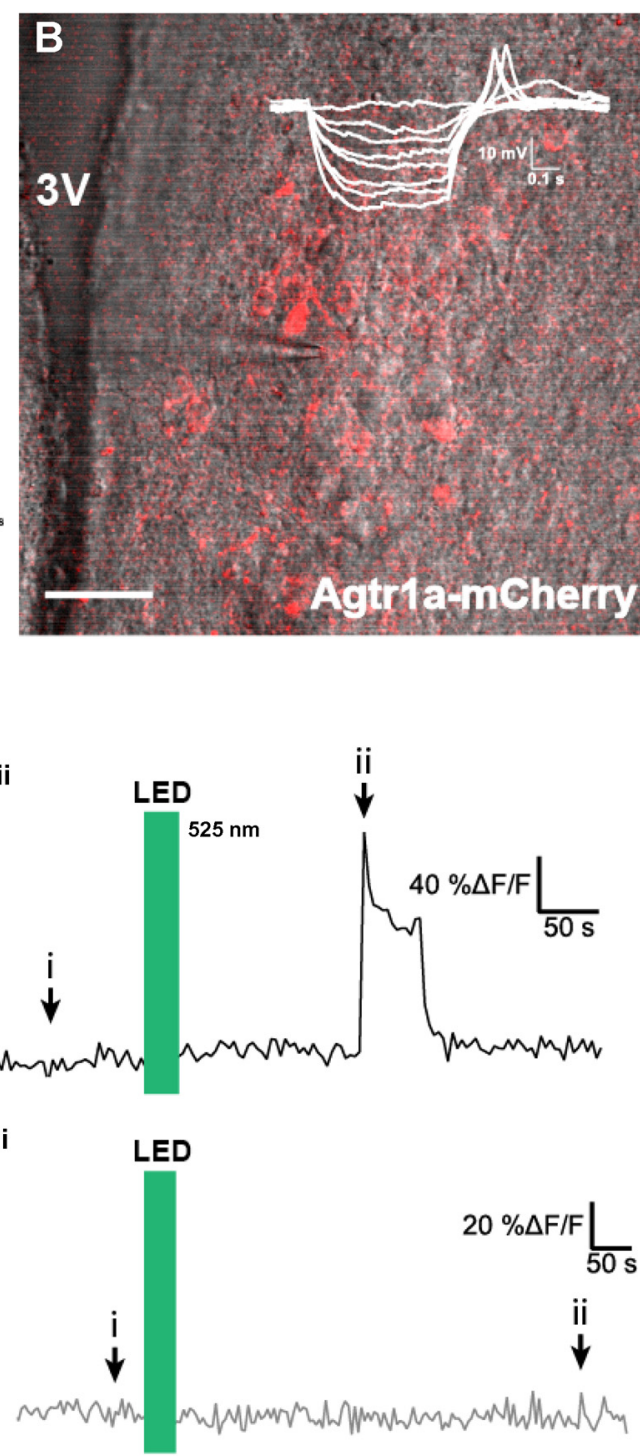

G

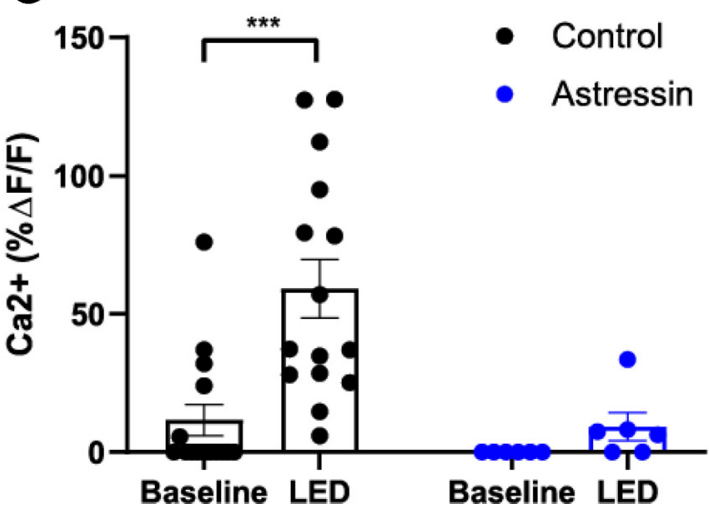

Figure 7. Optogenetic excitation of PVN ${ }^{A g t r 1 a}$ augments GCaMP7s fluorescence within PVN neurons that project to the RVLM. $\boldsymbol{A}$, Schematic of the AAV injections used to direct the expression of rsChR2-mCherry to PVN ${ }^{A g t r 1 a}$ while also driving retrograde expression of GCaMP7s in PVN neurons projecting to the RVLM. Fluorescence intensity is used as a proxy for neuronal firing and can be simultaneously recorded from multiple neurons in a slice through the PVN. B, Two-photon microscopy depicting PVN ${ }^{A g t r 1 a}$ expressing mCherry (red) and rsChR2 within coronal slice through the PVN captured using Dodt gradient contrast imaging. Inset, I-V curve with a low threshold depolarization, indicating the patched neurons exhibit electrophysiological characteristics of a parvocellular cell. 3V, Third ventricle. Scale bar, $50 \mu \mathrm{m}$. C, Further characterization of a patched PVN ${ }^{\text {Agtria }}$ neuron with different optogenetic stimulation protocols. Stimulus waveforms appear below the neuron's response. When pulse interval becomes too short, the spikes occur on the same depolarization, but spike count corresponds with LED pulses. A protocol consisting of 30 pulses with a $100 \mathrm{~ms}$ width and a $50 \mathrm{~ms}$ interval is the standard protocol used in these experiments unless otherwise noted. $\boldsymbol{D}$, GCaMP7s fluorescence within RVLM-projecting neurons ( $\boldsymbol{D}_{\boldsymbol{i}}$ ) under basal conditions and $\left(\boldsymbol{D}_{i i}\right)$ after LED stimulation of PVN ${ }^{\text {Agtrla }}$. Scale bar, $25 \mu \mathrm{m}$. $\boldsymbol{D}_{i i i}$, ROI trace from neuron shown in $\boldsymbol{D}_{i, i i}$ representing the time course of the increased GCamP7s fluores-

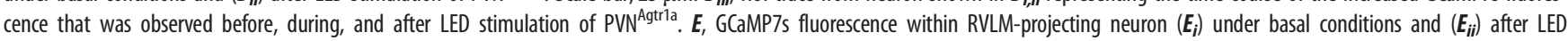



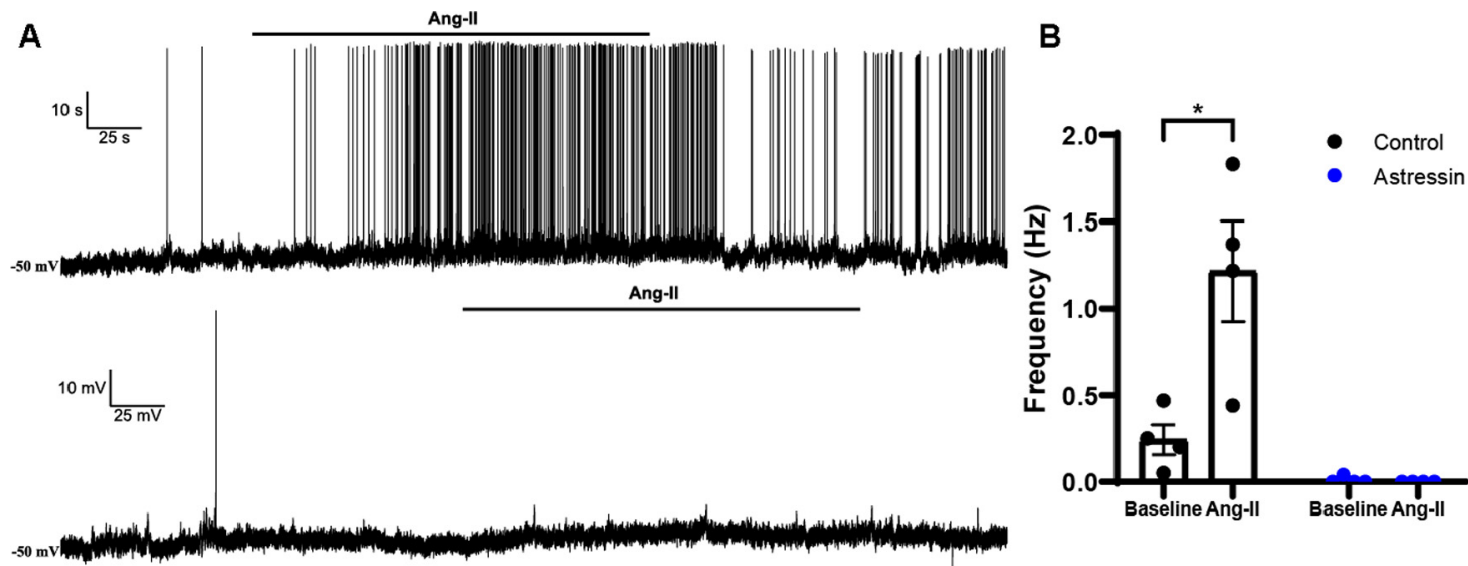

Figure 8. Blockade of $\mathrm{CRH} 1 \mathrm{R}(\mathrm{s})$ prevents the firing of PVN presympathetic neurons that follows administration of Ang-ll. $\boldsymbol{A}$, Representative electrophysiological recordings obtained from presympathetic neurons showing an Ang-II mediated increase in firing rate (top), an effect that was absent when slices were preincubated in Astressin (0.5 $\mu \mathrm{m})$ (bottom). $\boldsymbol{B}$, Left, Summary plots showing a significant increase in firing frequency evoked by Ang-ll under control conditions ( ${ }^{*} p=0.003$, two-way ANOVA followed by Tukey's post hoc test, $n=2$ of 4$)$; this effect that was blunted by Astressin ( $p=0.99$, two-way ANOVA followed by Tukey's post hoc test, $n=4$ cells from 2 animals). ${ }^{*} P<0.05$. Error bars indicate SEM.

blood pressure (Fig. 9A). Statistical analysis revealed significant depressor responses induced by Astressin $60 \mathrm{~s}$ following microinjection (Fig. 9B, Vehicle; $3.2 \pm 2.6 \mathrm{mmHg}$, Astressin; $1.7 \pm 1.3 \mathrm{mmHg},-6.9 \pm 3.1 \mathrm{mmHg},-5.9 \pm 1.7 \mathrm{mmHg}$ for 50 , 100 , and $200 \mu \mathrm{M}$, respectively $\left[F_{(3,260)}=13.66 ; p<0.0001\right], n=6$ per group). No effects were observed on heart rate (vehicle; $1.5 \pm 6.5 \mathrm{bpm}$, Astressin; $-4.1 \pm 5.5 \mathrm{bpm},-0.2 .3 \pm 4.5 \mathrm{bpm}$, $-4.2 \pm 6.0 \mathrm{bpm}$ for 50, 100, and $200 \mu \mathrm{M}$, respectively $\left[F_{(36,260)}=0.6888 ; p=0.9110\right], n=6$ per group). These results suggest that under basal conditions, CRHR1(s) in the PVN contribute to the tonic maintenance of blood pressure. To evaluate a role for presympathetic neurons in this effect, we combined ganglionic blockade via systemic administration of hexamethonium with microinjections of Astressin $(200 \mu \mathrm{M})$ into the PVN. As expected, microinjection of Astressin $(200 \mu \mathrm{M})$ significantly lowered blood pressure relative to administration of the vehicle; however, this effect was eliminated in the presence of hexamonethonium $(30 \mathrm{mg} / \mathrm{kg}$, i.p.; Fig. $9 C,-5.9 \pm 1.7$ vs $-0.3 \pm$ $1.1 \mathrm{mmHg}$ for Astressin pre $(n=6)$ and post $(n=4)$ hexamethonium, respectively $\left[F_{(1,98)}=4.25 ; p=0.0420\right)$.

These results demonstrate that the decreases in blood pressure that follow CRH1R antagonism in the PVN are dependent on the autonomic nervous system and suggest that CRH exerts an endogenous excitatory tone on presympathetic neurons. To investigate this possibility, we performed ex vivo experiments directly assessing the effects of Astressin on basal $\mathrm{Ca}^{2+}$ activity in retrogradely labeled presympathetic neurons expressing GCaMP7s. As shown in Figure 9D, we found that Astressin per se significantly blunted ongoing basal

$\leftarrow$

stimulation of PVN ${ }^{\mathrm{Agtr1} a}$ in the presence of Astressin $(0.5 \mu \mathrm{m})$. Scale bar, $25 \mu \mathrm{m}$. $\boldsymbol{E}_{\text {iiii }}$, Rol trace from neuron shown in $\boldsymbol{E}_{i, i i}$ representing the time course of GCamP7s fluorescence that was observed before, during, and after LED stimulation of PVN ${ }^{A g t r 1 a}$ when Astressin $(0.5 \mu \mathrm{m})$ is present. $\boldsymbol{F}$, Left, $\mathrm{Ca}^{2+}$ frequency (Hz), as indicated by GCaMP7s fluorescence within RVLMprojecting neurons, increases after LED stimulation of $\mathrm{PVN}^{\mathrm{Agtrla}}(p=0.001$, two-way ANOVA followed by Tukey's post hoc test, $n=15$ cells from 5 animals). Right, $\mathrm{Ca}^{2+}$ frequency (Hz) does not significantly increase after LED stimulation of PVN ${ }^{\text {Agtrla }}$ in the presence of Astressin ( $p=0.64$, two-way ANOVA followed by Tukey's post hoc test, $n=6$ cells from 3 animals). $\mathbf{G}$, Left, $\mathrm{Ca}^{2+}$ amplitude $(\% \Delta \mathrm{F} / \mathrm{F})$, as indicated by GCaMP7s fluorescence within RVLM-projecting neurons, increases after LED stimulation ( $p=0.0003$, two-way ANOVA followed by Tukey's post hoc test, $n=15$ cells from 5 animals). Right, $\mathrm{Ca}^{2+}$ amplitude (\% $\%$ F/F) does not significantly increase in the presence of Astressin ( $p=0.9$, two-way ANOVA followed by Tukey's post hoc test, $n=6$ cells from 3 animals).
$\mathrm{Ca}^{2+}$ activity in these neurons, drastically decreasing both $\mathrm{Ca}^{2+}$ transient frequency (Fig. $9 E ; t_{(6)}=3.46, p=0.01$, paired $t$ test, $n=7$ cells from 3 animals) and amplitude (Fig. $9 E ; t_{(6)}=4.54, p=0.004$, paired $t$ test, $n=7$ cells from 3 animals). These results further support the notion that endogenous CRH acts on CRHR1(s) expressed on presympathetic neurons to promote tonic excitation that contributes to the maintenance of blood pressure in male mice.

Final experiments tested the hypothesis that the elevations in blood pressure that follow in vivo optogenetic excitation of $\mathrm{PVN}^{\text {Agtrla }}$ results from the interneuronal cross-talk revealed by our anatomic and electrophysiological studies. Male Agtrla-Cre mice were again delivered Cre-inducible AAV-ChR2-eYFP into the PVN (Fig. 10A). After 3-4 weeks of recovery, mice were anesthetized, and a Millar catheter was implanted into the left common carotid artery. Subsequently, mice were placed into a stereotaxic apparatus, and a microcraniotomy was performed dorsal to the PVN, where a dual optrode/microinjection cannula was lowered above the PVN. This allowed microinjections and optogenetic stimulation within the same site while blood pressure was simultaneously recorded. Either vehicle (10\% acetic acid, $\mathrm{pH} 7.4)$ or Astressin $(200 \mu \mathrm{M})$ was microinjected into the PVN; and $5 \mathrm{~min}$ later, pulses of $473 \mathrm{~nm}$ laser light $(10 \mathrm{~mW}$ output; $20 \mathrm{~ms}$ pulse width; $30 \mathrm{~Hz} ; 1 \mathrm{~min}$ ) were delivered above the site of injection. As shown in Figure $10 B, C$, optogenetic excitation of PVN ${ }^{\text {Agtrla }}$ reliably produced a significant increase in blood pressure that was sustained until the cessation of illumination. This response was replicated when optical stimulation was performed $5 \mathrm{~min}$ following the administration of vehicle. Remarkably, the pressor response induced by optogenetic excitation of PVN ${ }^{\text {Agtrla }}$ was abolished by pretreatment with Astressin $(200 \mu \mathrm{M})$ (Fig. 10B,C; PVN ${ }^{\text {Agtrla-ChR2 }}$; $5.1 \pm 2.0 \mathrm{mmHg}, \quad \mathrm{PVN}^{\text {Agtr1a-ChR2 }}$ (acetic acid); $7.7 \pm 3.1 \mathrm{mmHg}$, $\mathrm{PVN}^{\text {Agtrla-ChR2 }}$ (Astressin); $-4.1 \pm 3.0 \mathrm{mmHg}, \quad\left[F_{(2,223)}=17.58\right.$; $p<0.0001], n=6$ per group). Together, these results support the overall notion that activity-dependent release of $\mathrm{CRH}$ from PVN $^{\text {Agtrla }}$ evokes a CRHR1-mediated excitatory response in presympathetic neurons that ultimately increases blood pressure in male mice.

\section{Discussion}

Stressors are met with coordinated neuroendocrine and autonomic responses to cope with the energetic demands of physiological and psychological threats. The present study unveils a 


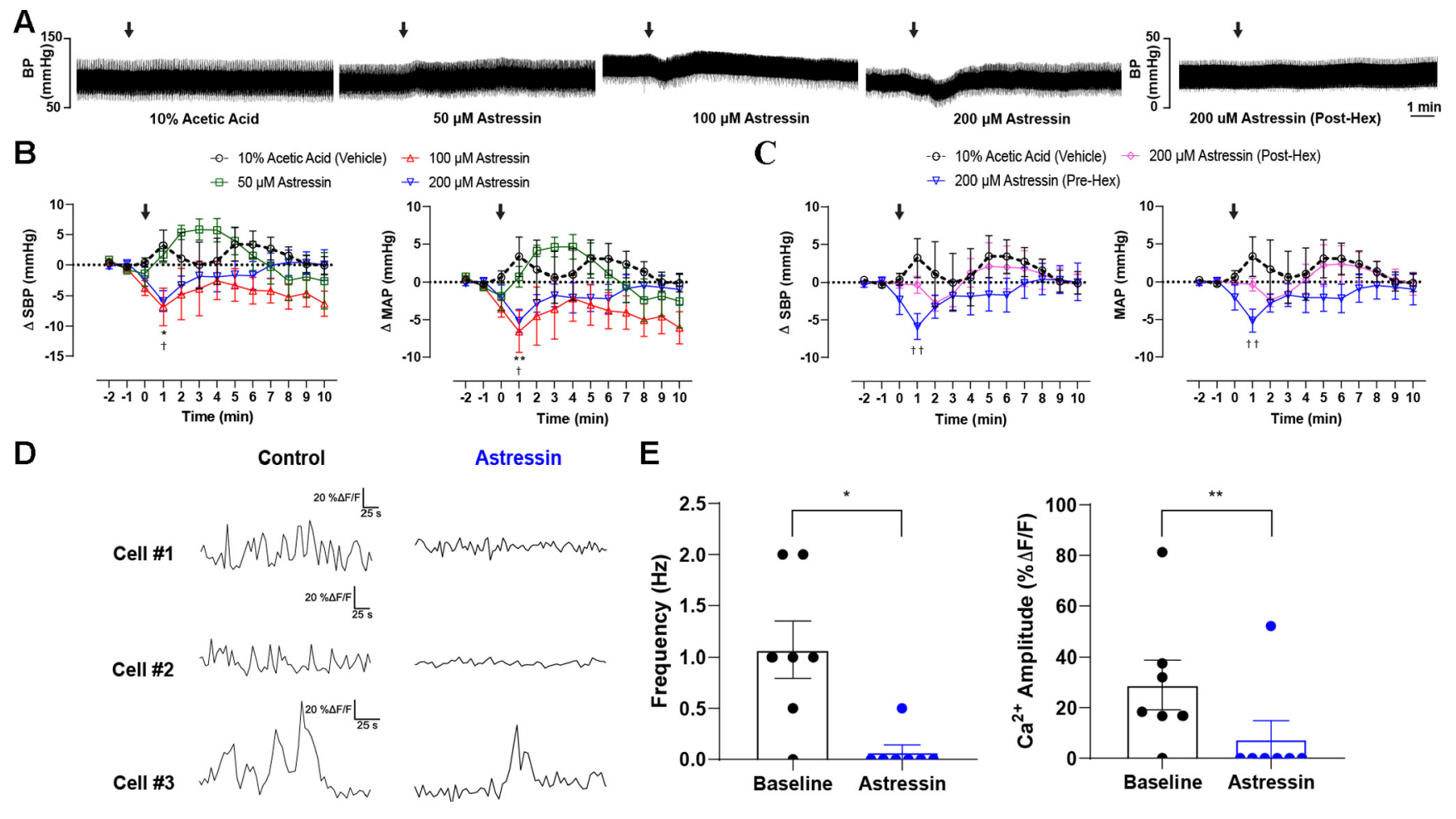

Figure 9. Blockade $\mathrm{CRH} 1 \mathrm{R}(\mathrm{s})$ in the PVN lowers basal blood pressure and diminishes the firing activity of presympathetic neurons. $A$, Representative pulsatile arterial blood pressure traces following PVN microinjection (100 nl) with vehicle, different doses of Astressin (50, 100, $200 \mu \mathrm{m})$, and Astressin following systemic administration of hexamethonium. $\boldsymbol{B}$, Grouped data demonstrating (left) the change in SBP and (right) mean arterial pressure (MAP) following the administration of vehicle and the different doses of Astressin into the PVN ( $n=6$ per group). C, PVN administration of Astressin $(200 \mu \mathrm{m})$ before $(n=6)$ or after $(n=4)$ the systemic administration of hexamethonium $\left(30 \mathrm{mg} / \mathrm{kg}\right.$, i.p.). ${ }^{*} p<0.05 ;{ }^{* * *} p<0.01$; two-way ANOVA followed by Tukey's post hoc test for vehicle versus Astressin $(100 \mu \mathrm{m}) .{ }^{\dagger} p<0.05 ;{ }^{+t} p<0.05$; two-way ANOVA followed by Tukey's post hoc test for vehicle versus Astressin (200 $\mu \mathrm{m}$ ). Arrows indicate time of injection. $\boldsymbol{D}$, Representative traces of basal GCaMP7s activity in three independent recordings obtained from RVLM-projecting neurons (left) before and (right) subsequent to delivery of Astressin (0.5 $\mu \mathrm{M}$ ). $\boldsymbol{E}$, Summary data showing mean changes in GCaMP7s transients (left) frequency and (right) amplitude evoked by Astressin administration ( $n=7$ cells from 3 animals). Error bars indicate SEM.

A

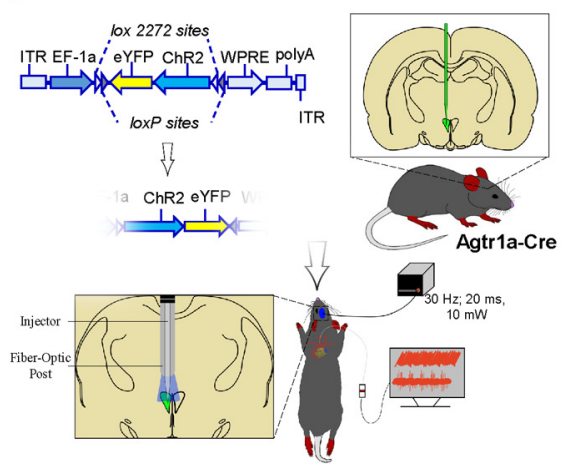

B

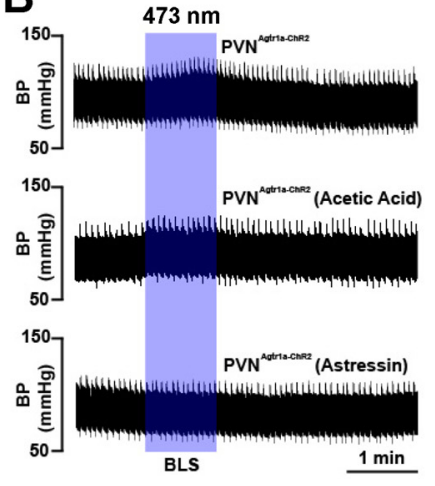

C

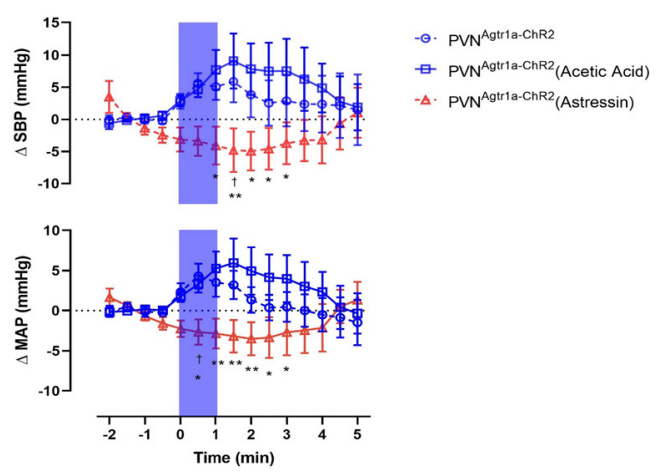

Figure 10. Blockade of $\mathrm{CRH} 1 \mathrm{R}(\mathrm{s})$ within the PVN abolishes the increased blood pressure evoked by the optogenetic stimulation of PVN ${ }^{\mathrm{Agtr} l a}$. $\boldsymbol{A}$, Schematic depicting the mouse line and experimental protocol. In this experiment, Agtr1a-Cre mice received a Cre-inducible AAV-ChR2-eYFP into the PVN. Following recovery, optogenetic stimulation $(10 \mathrm{~mW} ; 20 \mathrm{~ms}$ pulse width; $30 \mathrm{~Hz}$; $1 \mathrm{~min}$ ) of PVN ${ }^{\mathrm{Agtr} 1 \mathrm{a}}$ was performed after PVN microinjections using a dual optical injector cannula. $\boldsymbol{B}$, Representative pulsatile arterial blood pressure traces following blue laser stimulation

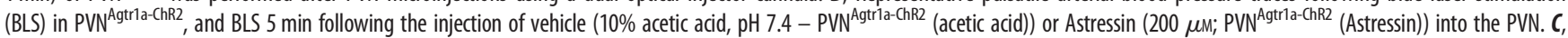
Grouped data demonstrating the change in SBP and mean arterial pressure (MAP). $* p<0.05 ; * * p<0.05$; two-way ANOVA followed by Tukey's post for PVN $N^{\text {Agtrla-ChR2 }}$ (Astressin) versus

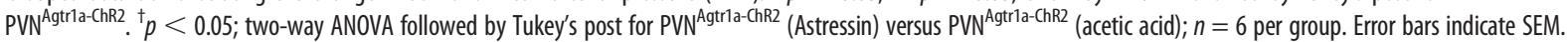

paracrine signaling mechanism within the PVN that couples the activity of neurosecretory and presympathetic neurons mediating these responses. In this regard, in vivo optogenetic excitation of PVN ${ }^{\text {Agtrla }}$ was found to significantly increase blood pressure, an effect that was dependent on recruitment of the autonomic nervous system. Puzzlingly, PVN ${ }^{\text {Agtrla }}$ did not exhibit characteristics of presympathetic neurons involved in the regulation of blood pressure but, rather, were $\mathrm{CRH}$-synthesizing neurons that initiate activation of the HPA axis. Intriguingly, fibers originating from $\mathrm{PVN}^{\mathrm{Agtrla}}$ made appositions onto presympathetic neurons that expressed mRNA coding for CRHR1(s), thereby providing anatomic and molecular evidence supporting a local cross-talk between these neuronal phenotypes. Indeed, ex vivo optogenetic excitation of PVN ${ }^{\text {Agtrla }}$ elicited increased firing of presympathetic neurons that persisted in the presence of glutamate receptor antagonists but was completely abolished by Astressin, a 
CRHR1 antagonist. Delivery of Astressin into the PVN significantly decreased blood pressure in vivo and suppressed basal $\mathrm{Ca}^{2+}$ activity within presympathetic neurons ex vivo, indicating that CRHR1(s) exert an excitatory tone on presympathetic neurons that contributes to the maintenance of blood pressure. Additionally, pretreatment with Astressin eliminated elevations in blood pressure that followed optogenetic excitation of $\mathrm{PVN}^{\text {Agtr1a }}$, demonstrating that $\mathrm{CRH}$ and its receptors couple the activity of neurosecretory and presympathetic neurons in the PVN. Collectively, these results reveal a novel mechanism underlying interneuronal cross-talk within the PVN that coordinates neuroendocrine release with autonomic outflow in male mice. Cross-talk among PVN ${ }^{\text {Agtrla }}$ and presympathetic neurons is likely engaged under conditions of increased RAS activity, such as hyponatremia, hypotension, or psychogenic stress, that elicit homeostatic multimodal responses involving coordinated HPA axis, autonomic and behavioral limbs orchestrated by the PVN. The implication is that chronic stress may promote cardiometabolic disease through dysregulation of the cross-talk revealed by our experiments.

Early studies using rats determined that electrical stimulation of the parvocellular subdivision of the PVN increases blood pressure and SNA (Porter and Brody, 1986; Kannan et al., 1989). Subsequently, it was reported that microinjections of Ang-II into the PVN also increase blood pressure and SNA, but this effect could be abrogated by Agtrla antagonists (Bains et al., 1992; Jensen et al., 1992; G. Q. Zhu et al., 2002; Y. F. Li et al., 2006). Consistent with these prior studies, our results demonstrate that optogenetic excitation of PVN ${ }^{\text {Agtrla }}$ elicits elevations in blood pressure that are dependent on engagement of the autonomic nervous system. These results suggest that, within the PVN, Ang-II acts on Agtrla(s) to increase firing of neurons that control autonomic outflow to cardiovascular tissues. Indeed, prior electrophysiological studies found that Ang-II depolarizes neurons in the PVN with identified projections to the hindbrain and spinal cord (Ferguson, 1988; D. P. Li et al., 2003; Cato and Toney, 2005), and our results showing that Ang-II increases the firing of presympathetic neurons are consistent with these earlier findings. A parsimonious explanation for these effects is that Ang-II binds to Agtrla(s) expressed on presympathetic neurons to evoke excitation; however, presympathetic neurons do not appear to express Agtrla(s); and consistent with prior reports, we found that PVN ${ }^{\text {Agtrla }}$ are parvocellular neurosecretory neurons that synthesize CRH (Oldfield et al., 2001; L. A. Wang et al., 2019). A recent study by Jiang et al. (2018) used genetically modified mice, in vitro patch-clamp electrophysiology, and viral tract tracing to convincingly demonstrate that functional CRH1R(s) are present on PVN neurons that project to the hindbrain. Here, we replicate these results by showing that PVN neurons that project to the RVLM express CRH1R mRNA. This, in conjunction with the observation that $\mathrm{PVN}^{\text {Agtrla }}$ produce $\mathrm{CRH}$ and make appositions onto presympathetic neurons, predicts cross-talk among these neuronal phenotypes that is mediated by CRH1R(s).

While each neuronal phenotype within the PVN can be linked to a distinct function, there is growing evidence that a local, interpopulation cross-talk among the neurons influences physiology and behavior (Brown et al., 2013; Son et al., 2013; Pati et al., 2020). Here, we used in vitro optogenetics with wholecell patch-clamp electrophysiology and $\mathrm{Ca}^{2+}$ imaging to reveal that selective activation of $\mathrm{PVN}^{\mathrm{Agtrla}}$ is followed by a significant increase in firing discharge of presympathetic neurons. The activation of the latter was slow and delayed in nature (tens of seconds following PVN ${ }^{\text {Agtr1a }}$ activation) and was not mediated by the fast-acting excitatory transmitter glutamate. Indeed, our results showing that the $\mathrm{PVN}^{\text {Agtrla }}$ to presympathetic neuronal cross-talk was blunted by Astressin support CRH as the key underlying signaling mediator. The slow temporal dynamics of this cross-talk is very similar to the cross-talk between AVP neurosecretory and presympathetic neurons we recently reported in the PVN (Son et al., 2013). We showed that the AVP to presympathetic cross-talk was mediated by dendritically released AVP and its diffusion into the extracellular space (Son et al., 2013). Still, whether the PVN ${ }^{\text {Agtrla }}$ to presympathetic neuronal crosstalk involves dendritic and/or axonal release of CRH remains to be determined. The fact that presympathetic neurons were activated following stimulation of PVN ${ }^{\text {Agtrla }}$ neurons either by direct optical stimulation or by Ang-II, the endogenous ligand of Agtrla, suggests that this cross-talk is not an artifactual response associated with optogenetic manipulations. Finally, indices of cross-talk among PVN ${ }^{\text {Agtrla }}$ and presympathetic neurons were observed in male mice as well as male rats, suggesting that this unique signaling mechanism coupling neuroendocrine secretion and autonomic outflow may be conserved across species.

Our present results, along with previous reports (Brown et al., 2013; Son et al., 2013; Pati et al., 2020), support the growing notion that neuropeptides are efficient signaling molecules mediating interneuronal communication within the PVN, contributing to the ability of this nucleus to generate complex, multimodal homeostatic responses. In this regard, administration of Astressin $(200 \mu \mathrm{M})$ into the PVN produced a transient, but significant, decrease in blood pressure that was eliminated by systemic hexamethonium, suggesting that $\mathrm{CRH}$ receptors in the PVN contribute to the maintenance of basal blood pressure by influencing autonomic outflow. In support of this interpretation, we found that ex vivo application of Astressin silenced $\mathrm{Ca}^{2+} \mathrm{ac}^{2}$ tivity within presympathetic neurons of the PVN, thereby revealing that $\mathrm{CRH}$ receptors exert a basal excitatory tone on presympathetic neurons that affects blood pressure. To the best of our knowledge, this is the first report of CRH receptor blockade within the PVN affecting basal blood pressure. Previous studies found that intracerebroventricular delivery of $\mathrm{CRH}$ increases blood pressure (Tarjan et al., 1995; Yosten and Samson, 2014) and selective delivery of CRH into the RVLM also increases blood pressure and SNA, effects that are blocked by pretreatment with Astressin (Bardgett et al., 2014). Our final experiments tested the hypothesis that elevations in blood pressure that followed optogenetic excitation of PVN ${ }^{\text {Agtrla }}$ were dependent on stimulation of $\mathrm{CRH}$ receptors. Consistent with this hypothesis, microinjection of Astressin into the PVN prevented increased blood pressure during optogenetic activation of $\mathrm{PVN}^{\text {Agtr1a }}$. These results are consistent with a recent report by $\mathrm{L}$. A. Wang et al. (2019), showing that optogenetic excitation of $\mathrm{CRH}$ neurons in the PVN increases blood pressure in mice by stimulating $\mathrm{CRH}$ receptors; however, the same study determined that optogenetic excitation of nerve terminals in the nucleus of the solitary tract that originated from $\mathrm{CRH}$ neurons in the PVN also increase blood pressure (L. A. Wang et al., 2019). While it is established that $\mathrm{CRH}$ neurons in the PVN project to hindbrain structures (e.g., nucleus of the solitary tract, RVLM) (Sawchenko, 1987; Milner et al., 1993), this pattern of innervation may not reflect that of $\mathrm{PVN}^{\text {Agtrla }}$, which represents a subset $(\approx 80 \%)$ of $\mathrm{CRH}$ neurons. The vast majority of $\mathrm{PVN}^{\text {Agtr1a }}$ project to the median eminence and control the activity of the HPA and HPT axes (de Kloet et al., 2017). Here, we propose that Agtrla(s) within the PVN couple the activity of these neuroendocrine axes 
to sympathetic outflow and blood pressure to coordinate metabolic and cardiovascular responses to stress in male mice.

Cross-talk among neurosecretory and presympathetic neurons of the PVN has important implications for cardiometabolic diseases. Stress is an established risk factor for cardiometabolic disease (Yusuf et al., 2004; Penninx, 2017), and impaired HPA axis activity and autonomic dysfunction are commonly observed in hypertension, myocardial infarction, obesity, and Type 2 diabetes (Lemche et al., 2016). Conversely, overactivation of the RAS is associated with stress-related pathologies, such as affective disorders (Baghai et al., 2006; Reinecke et al., 2018), which are often comorbid with diabetes, hypertension, and cardiovascular disease (Penninx, 2017; Wallace et al., 2018). Intriguingly, within the PVN, the expression of Agtrla(s) and CRH is upregulated subsequent to chronic stress (Aguilera et al., 1995; Herman et al., 1995; Leong et al., 2002), suggesting enhanced cross-talk among $\mathrm{PVN}^{\text {Agtrla }}$ and presympathetic neurons that couples heightened HPA axis activity to augmented sympathetic drive. Chronic engagement of neuroendocrine and autonomic limbs of the stress response contributes to the glucose intolerance and hypertension that is a hallmark of the metabolic syndrome. Thus, dysregulation of the cross-talk revealed by our experiments could be a contributing mechanism linking comorbidity between chronic stress and cardiometabolic disease, thereby representing a novel therapeutic target.

\section{References}

Aguilera G, Young WS, Kiss A, Bathia A (1995) Direct regulation of hypothalamic corticotropin-releasing-hormone neurons by angiotensin-II. Neuroendocrinology 61:437-444.

Baghai TC, Binder EB, Schule C, Salyakina D, Eser D, Lucae S, Zwanzger P, Haberger C, Zill P, Ising M, Deiml T, Uhr M, Illig T, Wichmann HE, Modell S, Nothdurfter C, Holsboer F, Müller-Myhsok B, Möller HJ, Rupprecht R, et al. (2006) Polymorphisms in the angiotensin-converting enzyme gene are associated with unipolar depression, ACE activity and hypercortisolism. Mol Psychiatry 11:1003-1015.

Bains JS, Potyok A, Ferguson AV (1992) Angiotensin II actions in paraventricular nucleus: functional evidence for neurotransmitter role in efferents originating in subfornical organ. Brain Res 599:223-229.

Bardgett ME, Sharpe AL, Toney GM (2014) Activation of corticotropinreleasing factor receptors in the rostral ventrolateral medulla is required for glucose-induced sympathoexcitation. Am J Physiol Endocrinol Metab 307:E944-E953.

Bourque CW, Oliet SH, Kirkpatrick K, Richard D, Fisher TE (1993) Extrinsic and intrinsic modulatory mechanisms involved in regulating the electrical activity of supraoptic neurons. Ann NY Acad Sci 689:512-519.

Brown CH, Bains JS, Ludwig M, Stern JE (2013) Physiological regulation of magnocellular neurosecretory cell activity: integration of intrinsic, local and afferent mechanisms. J Neuroendocrinol 25:678-710.

Cato MJ, Toney GM (2005) Angiotensin II excites paraventricular nucleus neurons that innervate the rostral ventrolateral medulla: an in vitro patch-clamp study in brain slices. J Neurophysiol 93:403-413.

Cazalis M, Dayanithi G, Nordmann JJ (1985) The role of patterned burst and interburst interval on the excitation-coupling mechanism in the isolated rat neural lobe. J Physiol 369:45-60.

Chen QH, Toney GM (2010) In vivo discharge properties of hypothalamic paraventricular nucleus neurons with axonal projections to the rostral ventrolateral medulla. J Neurophysiol 103:4-15.

Colmers PL, Bains JS (2018) Balancing tonic and phasic inhibition in hypothalamic corticotropin-releasing hormone neurons. J Physiol 596:19191929.

deBoer RW, Karemaker JM, Strackee J (1987) Hemodynamic fluctuations and baroreflex sensitivity in humans: a beat-to-beat model. Am J Physiol 253:H680-H689.

de Kloet AD, Wang L, Ludin JA, Smith JA, Pioquinto DJ, Hiller H, Steckelings UM, Scheuer DA, Sumners C, Krause EG (2016) Reporter mouse strain provides a novel look at angiotensin type-2 receptor distribution in the central nervous system. Brain Struct Funct 221:891-912. de Kloet AD, Wang L, Pitra S, Hiller H, Smith JA, Tan Y, Nguyen D, Cahill KM, Sumners C, Stern JE, Krause EG (2017) A unique 'angiotensin-sensitive' neuronal population coordinates neuroendocrine, cardiovascular, and behavioral responses to stress. J Neurosci 37:3478-3490.

Ferguson AV (1988) Paraventricular nucleus neurons projecting to the dorsomedial medulla are influenced by systemic angiotensin. Brain Res Bull 20:197-201.

Franklin KB, Paxinos G (2008) The mouse brain in stereotaxic coordinates, Ed 3. Amsterdam: Elsevier.

Frazier CJ, Harden SW, Alleyne AR, Mohammed M, Sheng W, Smith JA, Elsaafien K, Spector EA, Johnson DN, Scott KA, Krause EG, de Kloet AD (2021) An angiotensin-responsive connection from the lamina terminalis to the paraventricular nucleus of the hypothalamus evokes vasopressin secretion to increase blood pressure in mice. J Neurosci 41:1429-1442.

Herman JP, Adams D, Prewitt C (1995) Regulatory changes in neuroendocrine stress-integrative circuitry produced by a variable stress paradigm. Neuroendocrinology 61:180-190.

Holbein WW, Blackburn MB, Andrade MA, Toney GM (2018) Burst patterning of hypothalamic paraventricular nucleus-driven sympathetic nerve activity in ANG II-salt hypertension. Am J Physiol Heart Circ Physiol 314:H530-H541.

Jensen LL, Harding JW, Wright JW (1992) Role of paraventricular nucleus in control of blood pressure and drinking in rats. Am J Physiol 262:F1068F1075.

Jezova D, Ochedalski T, Kiss A, Aguilera G (1998) Brain angiotensin II modulates sympathoadrenal and hypothalamic pituitary adrenocortical activation during stress. J Neuroendocrinol 10:67-72.

Jiang Z, Rajamanickam S, Justice NJ (2018) Local corticotropin-releasing factor signaling in the hypothalamic paraventricular nucleus. J Neurosci 38:1874-1890.

Kannan H, Hayashida Y, Yamashita H (1989) Increase in sympathetic outflow by paraventricular nucleus stimulation in awake rats. Am J Physiol 256:R1325-R1330.

Koba S, Hanai E, Kumada N, Kataoka N, Nakamura K, Watanabe T (2018) Sympathoexcitation by hypothalamic paraventricular nucleus neurons projecting to the rostral ventrolateral medulla. J Physiol 596:4581-4595.

Krause EG, de Kloet AD, Scott KA, Flak JN, Jones K, Smeltzer MD, UlrichLai YM, Woods SC, Wilson SP, Reagan LP, Herman JP, Sakai RR (2011) Blood-borne angiotensin II acts in the brain to influence behavioral and endocrine responses to psychogenic stress. J Neurosci 31:15009-15015.

Leib DE, Zimmerman CA, Poormoghaddam A, Huey EL, Ahn JS, Lin YC, Tan CL, Chen Y, Knight ZA (2017) The forebrain thirst circuit drives drinking through negative reinforcement. Neuron 96:1272-1281.e1274.

Lemche E, Chaban OS, Lemche AV (2016) Neuroendocrine and epigenetic mechanisms subserving autonomic imbalance and HPA dysfunction in the metabolic syndrome. Front Neurosci 10:142.

Leong DS, Terron JA, Falcon-Neri A, Armando I, Ito T, Johren O, Tonelli LH, Hoe KL, Saavedra JM (2002) Restraint stress modulates brain, pituitary and adrenal expression of angiotensin II AT(1A), AT(1B) and AT(2) receptors. Neuroendocrinology 75:227-240.

Li DP, Chen SR, Pan HL (2003) Angiotensin II stimulates spinally projecting paraventricular neurons through presynaptic disinhibition. J Neurosci 23:5041-5049.

Li Z, Ferguson AV (1993) Subfornical organ efferents to paraventricular nucleus utilize angiotensin as a neurotransmitter. Am J Physiol Regul Integr Comp Physiol 265:R302-R309.

Li YF, Wang W, Mayhan WG, Patel KP (2006) Angiotensin-mediated increase in renal sympathetic nerve discharge within the PVN: role of nitric oxide. Am J Physiol Regul Integr Comp Physiol 290:R1035-R1043.

Luther J, Tasker JG (2000) Voltage-gated currents distinguish parvocellular from magnocellular neurones in the rat hypothalamic paraventricular nucleus. J Physiol 523:193-209.

Madwed JB, Albrecht P, Mark RG, Cohen RJ (1989) Low-frequency oscillations in arterial pressure and heart rate: a simple computer model. Am J Physiol 256:H1573-H1579.

Milner TA, Reis DJ, Pickel VM, Aicher SA, Giuliano R (1993) Ultrastructural localization and afferent sources of corticotropin-releasing factor in the rat rostral ventrolateral medulla: implications for central cardiovascular regulation. J Comp Neurol 333:151-167.

Oldfield BJ, Davern PJ, Giles ME, Allen AM, Badoer E, McKinley MJ (2001) Efferent neural projections of angiotensin receptor (AT1) expressing 
neurones in the hypothalamic paraventricular nucleus of the rat. J Neuroendocrinol 13:139-146.

Pati D, Harden SW, Sheng W, Kelly KB, de Kloet AD, Krause EG, Frazier CJ (2020) Endogenous oxytocin inhibits hypothalamic corticotrophinreleasing hormone neurones following acute hypernatraemia. J Neuroendocrinol 32:e12839.

Penninx BW (2017) Depression and cardiovascular disease: epidemiological evidence on their linking mechanisms. Neurosci Biobehav Rev 74:277286.

Porter JP, Brody MJ (1986) A comparison of the hemodynamic effects produced by electrical stimulation of subnuclei of the paraventricular nucleus. Brain Res 375:20-29.

Reinecke A, Browning M, Klein Breteler J, Kappelmann N, Ressler KJ, Harmer CJ, Craske MG (2018) Angiotensin regulation of amygdala response to threat in high-trait-anxiety individuals. Biol Psychiatry Cogn Neurosci Neuroimaging 3:826-835.

Saavedra JM, Ando H, Armando I, Baiardi G, Bregonzio C, Jezova M, Zhou J (2004) Brain angiotensin II, an important stress hormone: regulatory sites and therapeutic opportunities. Ann NY Acad Sci 1018:76-84.

Sawchenko PE (1987) Evidence for differential regulation of corticotropinreleasing factor and vasopressin immunoreactivities in parvocellular neurosecretory and autonomic-related projections of the paraventricular nucleus. Brain Res 437:253-263.

Sladek CD, Michelini LC, Stachenfeld NS, Stern JE, Urban JH (2015) Endocrine-autonomic linkages. Compr Physiol 5:1281-1323.

Smith JA, Wang L, Hiller H, Taylor CT, de Kloet AD, Krause EG (2014) Acute hypernatremia promotes anxiolysis and attenuates stress-induced activation of the hypothalamic-pituitary-adrenal axis in male mice. Physiol Behav 136:91-96.

Son SJ, Filosa JA, Potapenko ES, Biancardi VC, Zheng H, Patel KP, Tobin VA, Ludwig M, Stern JE (2013) Dendritic peptide release mediates interpopulation cross-talk between neurosecretory and preautonomic networks. Neuron 78:1036-1049.

Sonner PM, Lee S, Ryu PD, Lee SY, Stern JE (2011) Imbalanced $\mathrm{K}^{+}$and $\mathrm{Ca}^{2+}$ subthreshold interactions contribute to increased hypothalamic presympathetic neuronal excitability in hypertensive rats. J Physiol 589:667-683.

Stern JE (2001) Electrophysiological and morphological properties of pre-autonomic neurones in the rat hypothalamic paraventricular nucleus. J Physiol 537:161-177.
Swanson LW, Sawchenko PE (1980) Paraventricular nucleus: a site for the integration of neuroendocrine and autonomic mechanisms. Neuroendocrinology 31:410-417.

Tarjan E, Ferraro T, May CN (1995) Effect of ICV infusion of CRF on blood pressure and adrenal steroids in rabbits. Neuropeptides 28:325-331.

Tasić T, Djordjević DM, De Luka SR, Trbovich AM, Japundzõić-Žigon N (2017) Static magnetic field reduces blood pressure short-term variability and enhances baro-receptor reflex sensitivity in spontaneously hypertensive rats. Int J Radiat Biol 93:527-534.

Ulrich-Lai YM, Herman JP (2009) Neural regulation of endocrine and autonomic stress responses. Nat Rev Neurosci 10:397-409.

van den Pol AN (1982) The magnocellular and parvocellular paraventricular nucleus of rat: intrinsic organization. J Comp Neurol 206:317-345.

Wallace K, Zhao X, Misra R, Sambamoorthi U (2018) The humanistic and economic burden associated with anxiety and depression among adults with comorbid diabetes and hypertension. J Diabetes Res 2018:4842520.

Wang L, Hiller H, Smith JA, de Kloet AD, Krause EG (2016) Angiotensin type la receptors in the paraventricular nucleus of the hypothalamus control cardiovascular reactivity and anxiety-like behavior in male mice. Physiol Genomics 48:667-676.

Wang LA, Nguyen DH, Mifflin SW (2019) Corticotropin-releasing hormone projections from the paraventricular nucleus of the hypothalamus to the nucleus of the solitary tract increase blood pressure. J Neurophysiol 121:602-608

Yosten GL, Samson WK (2014) Separating thirst from hunger. In: Neurobiology of body fluid homeostasis: transduction and integration (De Luca LA Jr, Menani JV, Johnson AK, eds). Boca Raton, FL: CRC

Yusuf S, Hawken S, Ounpuu S, Dans T, Avezum A, Lanas F, McQueen M, Budaj A, Pais P, Varigos J, Lisheng L (2004) Effect of potentially modifiable risk factors associated with myocardial infarction in 52 countries (the INTERHEART study): case-control study. Lancet 364:937-952.

Zhu GQ, Patel KP, Zucker IH, Wang W (2002) Microinjection of ANG II into paraventricular nucleus enhances cardiac sympathetic afferent reflex in rats. Am J Physiol Heart Circ Physiol 282:H2039H2045.

Zhu Q, Guo SY, Gong S, Yin QZ, Hisamitsu T, Jiang XH (2005) Losartan blocks the excitatory effect of peripheral hypertonic stimulation on vasopressinergic neurons in hypothalamic paraventricular nucleus in rats: electrophysiological and immunocytochemical evidence. Neurosci Lett 380:12-16. 